\title{
Genome-wide analysis and expression characteristics of small auxin-up RNA (SAUR) genes in moso bamboo (Phyllostachys edulis)
}

\begin{tabular}{|r|l|}
\hline Journal: & Genome \\
\hline Manuscript ID & gen-2016-0097.R1 \\
\hline Date Submitted by the Author: & 16-Aug-2016 \\
\hline Complete List of Authors: & $\begin{array}{l}\text { Bai, Qingsong; International Center for Bamboo and Rattan } \\
\text { Hou, Dan; International Center for Bamboo and Rattan } \\
\text { Li, Long; International Center for Bamboo and Rattan } \\
\text { Cheng, Zhanchao; International Center for Bamboo and Rattan } \\
\text { Ge, Wei; International Center for Bamboo and Rattan } \\
\text { Liu, Jun; International Center for Bamboo and Rattan } \\
\text { Li, Xueping; International Center for Bamboo and Rattan } \\
\text { Mu, Shaohua; International Center for Bamboo and Rattan } \\
\text { Gao, Jian; International Center for Bamboo and Rattan }\end{array}$ \\
\hline Keyword: & Phyllostachys edulis, PheSAUR, shoot growth, IAA, qRT-PCR \\
\hline
\end{tabular}




\section{Genome-wide analysis and expression characteristics of small auxin-up RNA (SAUR) genes in moso bamboo}

\section{(Phyllostachys edulis)}

Qingsong Bai ${ }^{\#}$, Dan Hou ${ }^{\#}$, Long Li, Zhanchao Cheng, Wei Ge, Jun Liu, Xueping Li, Shaohua Mu *, Jian Gao *

International Center for Bamboo and Rattan, Key Laboratory of Bamboo and Rattan Science and Technology, State Forestry Administration, Beijing, People's Republic of China.

Mailing address: No. 8, Wangjing Futong East Street, Chaoyang District, Beijing, China.

Jian Gao, e-mail: gaojianicbr@163.com, phone number: +86-010-84789801.

\# These authors contributed equally to this work.

* Corresponding Author. 
Abstract: Moso bamboo (Phyllostachys edulis) is well-known for its rapid shoot growth. Auxin exerts pleiotropic effects on plant growth. The small auxin-up RNA (SAUR) genes are early auxin-responsive genes involved in plant growth. In total, 38 SAUR genes were identified in P. edulis (PheSAUR). A comprehensive overview of the PheSAUR gene family is presented, including the gene structures, phylogeny and subcellular location predictions. A transcriptome analysis indicated that 37 (except PheSAUR18) of the PheSAUR genes were expressed during shoot growth process and the PheSAUR genes were differentially expressed. Furthermore, quantitative real-time PCR analysis indicated that all of the PheSAUR genes could be induced in different tissues of seedlings and that 37 (except PheSAUR41) of the PheSAUR genes were up-regulated after indole-3-acetic acid (IAA) treatment. These results reveal a comprehensive overview of the PheSAUR gene family and may pave the way for deciphering their functions during bamboo development.

Keywords: Phyllostachys edulis; PheSAUR; shoot growth; IAA; qRT-PCR 


\section{Introduction}

Moso bamboo (Phyllostachys edulis) is a large woody bamboo in Asia, and the most economically important bamboo in China. Under suitable conditions, the shoots can grow from 0 to 20 meters in less than 3 months (Peng et al. 2010 ; Peng et al. 2013a). Mountains of lumber are produced in the process. However, research was focused on the growth mode and shoot anatomical structures (Murphy and Alvin 1992; Lin et al. 2002). Thus, what actually happens to moso bamboo during its rapid growth process and what regulates the internal mechanisms? These questions are attracting scientific interest.

The plant hormone exerts a pleiotropic effect on various aspects of plant growth and development, including cell elongation, cell division, differentiation, root initiation, apical dominance and tropic responses. Auxin mediates these effects at the molecular level by altering the expression levels of numerous genes (Abel and Theologis 1996; Hagen and Guilfoyle 2002). One of the vital auxin-responsive families is the small auxin-up RNA (SAUR) gene family. SAUR genes have been identified in mung bean (Yamamoto et al. 1992), pea (Guilfoyle et al. 1993), tomato (Zurek et al. 1994), Arabidopsis (Gil et al. 1994), apple (Watillon et al. 1998), radish (Ann et al. 1998), maize (Yang and Poovaiah 2000), rice (Jain et al. 2006b), moss (Rensing et al. 2008), sorghum (Wang et al. 2010), potato, tobacco, pepper, petunia (Wu et al. 2012), cotton (Yang et al. 2012), litchi (Kuang et al. 2012), peach (Tatsuki et al. 2013), poplar (Wang et al. 2014) and citrus (Xie et al. 2015). Until now, no SAUR gene had been reported in P. edulis (PheSAUR).

SAUR can be induced by the application of exogenous auxin. These auxin-induced genes then control downstream genes. Most of the biological functions of $S A U R$ genes are focused on hypocotyl growth stem elongation and altering auxin transport. Recently, the biological mechanism of the SAUR genes was demonstrated in promoting cell expansion in Arabidopsis. SAUR19 subfamily (AT5G18010, AT5G18020, AT5G18030, AT5G18050, AT5G18060 and AT5G18080) proteins could provide a mechanistic link between auxin and plasma membrane $\mathrm{H}^{+}$-ATPases in Arabidopsis (Spartz et al. 
2014; Ren and Gray 2015). The SAUR19 protein (AT5G18010) also interacts with the PP2C-D subfamily of the type 2C protein phosphatases and negatively regulates plasma membrane H+-ATPase activity (Spartz et al. 2014). SAUR76, 77 and 78 (AT5G20820, AT1G17345 and AT1G72430) were identified as associating with the ethylene receptors ethylene response 2 and ethylene insensitive. These proteins could be induced by auxin and ethylene (Li et al. 2015). However, the overexpression of SAUR39 (LOC_Os09g37330) in rice showed lower shoot and root growth, altered shoot morphology, smaller vascular tissues, and lower yields (Kant et al. 2009). AtSAUR36 (AT2G45210) had been reported to be involved in the promotion of leaf senescence in Arabidopsis (Hou et al. 2013).

The SAUR gene family contains numerous auxin-response genes in different species, including 81 SAURs (with 2 pseudogenes) in Arabidopsis (Hagen and Guilfoyle 2002), 58 SAURs (with 2 pseudogenes) in rice (Jain et al. 2006), 18 SAURs in moss (Rensing et al. 2008), 71 SAURs in sorghum (Wang et al. 2010), 134 SAURs in potato, 99 SAURs in tomato (Wu et al. 2012), 79 SAURs in maize (Chen et al. 2014) and 70 SAURs in citrus (Xie et al. 2015). These reports also reported their main functions in these species. The most prevalently demonstrated function of the SAUR genes is in promoting plant growth. P. edulis is a bamboo with rapid shoot growth, which is its most significant characteristic. SAUR genes may play the same functions in bamboo.

The fast growing speed in moso bamboo is uncommon in plant species. However, the mechanism of rapid growth is still obscure in bamboo. Transcriptome analysis of moso bamboo shoots would provide important information in revealing the mechanism on the whole side (Peng et al. 2013b). But the detailed genes involved in the growing process are still not clear. SAUR gene family is one of the important gene families in auxin signaling and was never reported in bamboo. Identification of PheSAUR genes in moso bamboo is necessary for revealing the mechanism of rapid growing. Here, a genome-wide analysis of the PheSAUR genes could provide detailed information on the most numerous early auxin-responsive gene family. 


\section{Materials and Methods}

\section{Searching for $P$. edulis $S A U R$ family genes}

Bamboo genome database (http://www.bamboogdb.org/) resources were used for the identification of putative SAURs in bamboo (Zhao et al. 2014). The coding sequences and amino acid sequences of Arabidopsis and rice SAUR genes and proteins were downloaded from The Arabidopsis Information Resource (https://www.arabidopsis.org/) and Genome Annotation Project Database (http://rice.plantbiology.msu.edu/) (Lamesch et al. 2012; Kawahara et al. 2013). BLAST search algorithms BLASTP and BLASTN were used to identify putative PheSAURs in bamboo using Arabidopsis (AtSAUR), rice SAUR (OSSAUR) coding and protein sequences as queries. Pfam 02519 in the Pfam database (http://www.ncbi.nlm.nih.gov/Structure/cdd/wrpsb.cgi) was used to confirm each predicted PheSAUR protein (with cut off e-value of $\mathrm{e}^{-5}$ ) sequence (Marchler-Bauer et al. 2014).

\section{Phylogenetic analysis of PheSAUR genes}

A multiple sequence alignment analysis was conducted using the ClustalX (version 2.1) program with default parameters (Larkin et al. 2007). The phylogenetic analysis was carried out using the neighbor-joining method, and the unrooted tree was displayed using the Mega6.0 program (Tamura et al. 2013). Bootstrap values (above 50\%) from 1000 replicates are indicated at each node.

\section{Structure and sequence analysis of PheSAUR genes}

All of the $P$. edulis genome and coding sequences were obtained from the bamboo genome database. The Gene Structure Display Server (http://gsds1.cbi.pku.edu.cn/index.php) was used to analyze the gene structures (Guo et al. 2007).

The 1,500 bp of genomic sequences upstream of the $5^{\prime}$ untranslated regions (UTR) of each gene were downloaded for an 
upstream element searching. Plant CARE (http://bioinformatics.psb.ugent.be/webtools/plantcare/html/), a database of plant cis-acting regulatory DNA elements, was used to identify auxin-responsive elements (Lescot et al. 2002). The downstream (DST) elements were searched manually for the presence of conserved nucleotides in the $3^{\prime} \mathrm{UTR}$ of each PheSAUR retrieved from the bamboo genome database. The conserved consensus motifs in PheSAUR, OsSAUR and AtSAUR proteins were searched by MEME (http://meme-suite.org/) (Bailey et al. 2006). IMEter v2.0 (http://korflab.ucdavis.edu/cgi-bin/web-imeter2.pl) was used to calculate the intron-mediated enhancement (IME) signals in introns (Parra et al. 2011). CELLO v2.5 Server (http://cello.life.nctu.edu.tw/) was used to predict the probable protein localization for candidate PheSAURs (Yu et al. 2004).

\section{The top internodes of $P$. edulis shoots and culms at different heights}

The top internodes of $P$. edulis shoots and culms at $0.1,1,3,6,9,12,15$ (control) meters were collected in Anhui Province, China, where is a natural distribution area. Eight different heights of shoots and the culm after leaf expansion were selected in accordance with the developmental stages of $P$. edulis. Subsequently, each sample was cut from the tissue located in the basal part of the internodes, and finally collected. These materials were used for the transcriptome analysis of PheSAUR genes.

\section{Seedlings of $P$. edulis used for qRT-PCR}

P. edulis seedlings were grown in vermiculite in a growth chamber $\left(26^{\circ} \mathrm{C}\right.$ for $16 \mathrm{hlight} / 18^{\circ} \mathrm{C}$ for $8 \mathrm{~h}$ dark $)$ for 2 months.

For the auxin treatment, IAA was dissolved with dimethyl sulphoxide (DMSO) and then made as IAA solution. 1 mM IAA was irrigated into vermiculite. The leaves, stems and roots of these seedlings were collected at $0,1,3$ and 5 hours after IAA treatment. These materials were promptly transferred into liquid nitrogen for quantitative real-time PCR (qRT-PCR). Three independent biological replicates were made. 


\section{RNA isolation, transcriptome sequencing and relative expression level analysis of PheSAUR genes}

Total RNA was extracted using the TRIzol reagent (Invitrogen, USA). The quality and quantity of purified RNA was initially assessed on an agarose gel using a NanoDrop 8000 spectrophotometer (NanoDrop, Thermo Scientific, Germany), and then the integrity of RNA samples was further evaluated using an Agilent 2100 Bioanalyzer (Agilent Technologies, USA).

Top internodes of shoots from 8 different heights $(0.1 \mathrm{~m}, 0.5 \mathrm{~m}, 1 \mathrm{~m}, 3 \mathrm{~m}, 6 \mathrm{~m}, 9 \mathrm{~m}, 12 \mathrm{~m}$ and control $(15 \mathrm{~m}))$ of moso bamboos were collected. The RNA-seq libraries of 8 different samples for transcriptome sequencing were constructed according to the Illumina kit instructions (Illumina, San Diego, CA, USA). The library was sequenced to generate 101-nt paired-end reads using Illumina HiSeqTM2000 at Macrogen in Shenzhen, China. RNA-seq with a quality score of Phred $\geqslant$ 20 were indexed, trimmed, and aligned. Clean reads were aligned to the moso bamboo genome. Cufflinks was used to measure the relative abundance of transcripts by FPKM method (Fragments Per Kilobase of exon model per Million mapped reads). The FPKM values were used to analyze the relative expression levels of PheSAUR genes in shoot growth.

For qRT-PCR, Primer 3 web (version4.0.0, http://primer3.ut.ee/) was used to design the specific primers based on the SAURs 3' untranslated regions and coding sequences (Untergasser et al. 2012). The primers of all the PheSAUR genes used for were listed (Table S3). Tonoplast intrinsic protein 41 gene (TIP41) was used as a control (Fan et al. 2013). The qRT-PCR reactions were carried out with the Light Cycler480 System (Roche, USA) using the SYBR Premix EX TaqTM kit (Roche, USA). The following amplification reactions were performed for qRT-PCR: $95^{\circ} \mathrm{C}$ for 10 seconds, $60^{\circ} \mathrm{C}$ for 10 seconds, and $72^{\circ} \mathrm{C}$ for 20 seconds. The experiments were repeated 3 times with independent cDNA samples. The expression levels of PheSAUR genes are presented using fold change values transformed to log2 format compared to controls. Data were analyzed using Roche manager software and the relative figures were plotted by Sigma Plot 10.0. 


\section{Results}

\section{SAUR family members in P. edulis}

SAUR is a large gene family that contains over 70 members in Arabidopsis thaliana and 58 members in Oryza sativa. The P. edulis SAUR family sequences were obtained by searching annotations in the Bamboo Genome Datebase. A total of 44 sequences were obtained. Finally, proteins of all the 44 genes were confirmed by a Pfam search for the presence of an auxin-inducible signature conserved in coding sequences or amino acid sequences. A total of 38 PheSAUR genes were obtained. The length of amino acid sequences ranged from 83 to 1148. PheSAUR proteins possess a predicted molecular mass ranging from 8.88 to $128.04 \mathrm{kDa}$ and theoretical isoelectric point (pl) ranging from 5.47 to 11.91 (Table 1).

\section{Phylogenetic relationships of PheSAUR genes}

To explore the evolutionary expansion of PheSAURs in the bamboo genome, an unrooted tree was constructed from an alignment of their full-length protein sequences. This analysis revealed that all of the PheSAURs grouped broadly into four clusters, containing 16, 15, 3 and 4 members respectively, with well-supported bootstrap values (Fig. 1). Among the 38 PheSAURs, 15 sister pairs were formed, 8 (PheSAUR9 and PheSAUR42, PheSAUR11 and PheSAUR13, PheSAUR19 and PheSAUR24, PheSAUR1 and PheSAUR37, PheSAUR41 and PheSAUR44, PheSAUR5 and PheSAUR23, PheSAUR7 and PheSAUR8, and PheSAUR31 and PheSAUR36) of which had very strong bootstrap support (95\%). These results suggest that the expansion of PheSAUR genes through gene duplications was probably. The duplications of PheSAUR genes may be explained as maintaining a proper relationship with other interacting proteins (Jain et al. 2006a; Remington et al. 2004).

To examine the phylogenetic relationship of PheSAUR, OsSAUR and AtSAUR proteins, an unrooted tree was constructed from an alignment of their full-length protein sequences (Fig. 2). The bamboo PheSAUR proteins were clustered distinctly 
into 5 groups along with OsSAURs and AtSAURs. In addition, this analysis revealed that most OsSAURs and PheSAURs clustered in species-specific distinct clades. This result indicates that most OsSAURs and PheSAURs expanded in a species-specific manner.

\section{Structure and sequence analysis of PheSAUR genes}

Gene structures of the PheSAURs were showed in Fig. 1. Six of these genes contain introns, and 2 of them possess more introns (2 introns in PheSAUR37 and 18 introns in PheSAUR42). Eight PheSAUR CDS were not complete. The lengths of untranslated regions (UTR) were showed (Table S1).

We calculated the intron-mediated enhancement (IME) signals in 6 PheSAUR genes containing introns using IMEter v2.0, which calculates whether an intron is likely to enhance gene expression. Our results showed that introns of 3 PheSAUR genes (PheSAUR1, PheSAUR43 and PheSAUR32) had high scores (Table 1). By using CELLO v2.5 Server, it was found that 21 and 20 PheSAUR proteins possess signal sequences for targeting the nucleus and mitochondria. Some other members were predicted to localize to cytoplasmic and plasma membrane.

To understand the biological functions of the PheSAURs, an investigation of the 1,500 bp upstream sequences in PheSAURs, which represents their promoter region, using plantCARE and a manual search revealed the presence of a few to several putative auxin-responsive elements in most of them (Table 1). Some putative auxin-responsive cis-elements were identified in the promoter regions of the $S A U R$ genes in bamboo, suggesting that these $S A U R S$ might be involved in the auxin signal-transduction pathway.

The sequence ATAGAT (or a variation only at the first nucleotide position) and GTA regions were simultaneously identified in 20 PheSAUR genes in their 3'UTR (Table S2), and were perceived as the binding sites of downstream (DST) elements. The DST elements could induce $S A U R$ mRNA instability. Hence, the expression levels of PheSAUR genes could 
be regulated at the mRNA level.

Previous studies proved that most of SAUR proteins contain a conserved SAUR-specific domain (SSD) of approximately 60 residues in the central region (Park et al. 2007). Here, the conserved motif distributions in PheSAUR, OsSAUR and AtSAUR proteins were analyzed using MEME tool. Three extremely conservative motifs (motifs I-III) were simultaneously found in 157 or more proteins out of all the 172 tested SAUR proteins (Fig. S1).

\section{PheSAUR gene expression levels at internodes of shoots at different heights}

To gain insight into the functions and expression levels of PheSAURs in different growth and developmental processes, transcriptome sequencing data from the developing top internodes of bamboo shoots were used to analyze PheSAURs (Fig.

3). According to transcriptome sequencing data, one gene was not expressed during the shoot growth process and the Fragments Per Kilobase of exon model per Million mapped reads (FPKM) data for most of the genes were lower than 5 during this process (Table S4). PheSAUR18 was not expressed during this process. Some genes were differentially expressed. In the period of cell division (0.5-1 m), some PheSAUR genes (PheSAUR15, PheSAUR20, PheSAUR21, PheSAUR22 and PheSAUR29) were specifically expressed. In the fast growing period (3-9 m) in moso bamboo shoots, numerous PheSAUR genes (PheSAUR2, PheSAUR7, PheSAUR8, PheSAUR23, PheSAUR25, PheSAUR26, PheSAUR34 and PheSAUR35) were particularly expressed.

\section{Expression characterization of PheSAUR genes in seedlings and after IAA treatment}

The expression profiles of all of the PheSAUR genes were experimentally verified using quantitative real-time PCR (qRT-PCR) analysis (Fig. 4 and Fig. 5). Most of the PheSAUR genes were activated within $1 \mathrm{~h}$ in at least one organ following the IAA treatment, although to varying degrees (Fig. 4). Of the 38 PheSAUR genes, 36 (except PheSAUR9 and 
PheSAUR41) were activated after the IAA treatment in at least one organ. Four genes (PheSAUR5, PheSAUR15, PheSAUR31 and PheSAUR36) PheSAUR genes were specifically up regulated in the leaves after IAA treatment.

Expression levels of three organs from $P$. edulis seedlings were also showed (Fig. 5). All of the genes were expressed in leaves, stems and roots. However, some PheSAURs showed organ-/tissue-specific expression patterns in bamboo. PheSAUR2, PheSAUR15, PheSAUR20, PheSAUR28 and PheSAUR35 were specifically expressed in stems. PheSAUR4, PheSAUR6, PheSAUR9, PheSAUR17, PheSAUR26, PheSAUR37 and PheSAUR44 were mainly expressed in leaves. PheSAUR18 and PheSAUR36 exhibited higher expression levels in roots than in the other organs.

\section{Discussion}

\section{SAUR gene structure and intron functions}

Previous researchers have identified and annotated some SAUR genes in Arabidopsis, rice, Physcomitrella, sorghum and Solanaceae (Hagen and Guilfoyle 2002; Jain et al. 2006b; Rensing et al. 2008; Wang et al. 2010; Wu et al. 2012). In this study, we identified 38 SAUR genes in moso bamboo. All of the members were predicted to encode $S A U R$ domains. Interestingly, most of the PheSAURs are intronless (Table 1). This phenomenon also exists in the $S A U R$ genes of other species (Jain et al. 2006b; Rensing et al. 2008; Wang et al. 2010; Wu et al. 2012). Potential function of introns, such as a signal for mRNA export, and alternative splicing-based exon shuffling has been revealed (Fedorova and Fedorov 2003; Roy and Gilbert 2006). In addition, many introns also have the ability to promote gene expression through a process termed IME (Mascarenhas et al. 1990). The PheSAUR genes with high scored IME implying that these introns are expected to enhance expression. Many studies have indicated that introns may play an important role in genetic evolution and have potential functions (Fedorova and Fedorov 2003; Lecharny et al. 2003; Roy and Gilbert 2006). 


\section{Evolution of PheSAUR genes}

Moso bamboo has 24 pairs of chromosomes, twice that of rice. However, rice contains at least 20 more SAUR genes (58) than moso bamboo (38). It is not clear when these species differentiate. However, PheSAUR genes could be divided into several models according to relative expression levels, which meant redundancy not only in moso bamboo, but also in the evolutionary history of the SAUR gene family. Interestingly, the coding sequence of PheSAUR42 was 3,447 bp, which is unusually long for the SAUR family.

\section{Regulation of PheSAUR genes}

Gene expression can be regulated during DNA transcription and RNA processing or at the mature RNA and protein translation levels. The SAUR gene family is particular because of the DST elements. The DST element in the 3' UTR could contribute to the instability of SAUR mRNA. Hence, there is a particular regulatory process for SAUR gene expression at the mRNA level (Newman et al. 1993). The exact consensus DST element of ATAGAT (or a variation only at the first nucleotide position) and GTA regions were identified in 20 PheSAUR genes. The DST elements could be identified in 12 OsSAUR gene family sub-groups. The ratio of genes containing DST elements in P. edulis was more than twice that in Oryza sativa. The presence of a DST element in the downstream region of OSSAURs may be responsible for the instability of their mRNAs and thereby regulate their expression. Partial mRNAs encoded by SAUR genes were highly unstable because of the DST elements in their 3'UTRs (Newman et al. 1993; Sullivan et al. 1996; Jain et al. 2006b), which is thought to be a common regulatory mechanism in the SAUR gene family. The SAUR proteins (SAUR19 subfamily) in Arabidopsis were proved to be highly unstable. However, the addition of an N-terminal (GFP or strep) tag and a C-terminal (GFP or GUS) tag increased the stability of SAUR19 subfamily proteins and SAUR63, respectively (Chae et al. 2012; Spartz et al. 2012). 


\section{Expression levels of PheSAUR genes}

PheSAUR15, PheSAUR20, PheSAUR21, PheSAUR22 and PheSAUR29, which were specially expressed at 0.5-1 m, may be involved in cell division in shoot growth. PheSAUR genes (PheSAUR2, PheSAUR7, PheSAUR8, PheSAUR23, PheSAUR25, PheSAUR26, PheSAUR34 and PheSAUR35), which were particularly expressed at 3-9 m, suggest that they may play important roles in promoting shoot elongation.

According to qRT-PCR, 7 (PheSAUR4, PheSAUR6, PheSAUR9, PheSAUR13, PheSAUR17, PheSAUR26, PheSAUR37), 5 (PheSAUR2, PheSAUR15, PheSAUR20, PheSAUR28 and PheSAUR35) and 2 (PheSAUR11, PheSAUR18) PheSAUR genes showed leaf-, stem- and root-specific expression, respectively, which indicates that these genes may play significant roles in different organs. Most of the genes were up-regulated in leaves and roots indicating that leaves and roots were the more important growing parts of $P$. edulis seedlings. More auxin may be produced in the leaves and roots to maintain plant growth in seedlings. As determined by qRT-PCR, most of the PheSAUR genes were up-regulated from 0 to 5 hours, implying that these genes were more likely to play critical roles in regulating IAA responses in leaves and roots. Specifically up regulated PheSAUR genes (PheSAUR5, PheSAUR15, PheSAUR31 and PheSAUR36) in leaf may be involved in the developments of leaf in P. edulis seedlings. PheSAUR27 may be involved in growth of stem. No root specifically up regulated PheSAUR genes were detected and most genes (except PheSAUR5, PheSAUR15, PheSAUR16, PheSAUR27, PheSAUR31, PheSAUR36 and PheSAUR41) were up regulated in root. These genes may be involved in the growth of root.

\section{Putative functions of PheSAUR genes}

Due to the important character of fast growing, growing mechanism of moso bamboo was urgently needed to study. The SAUR gene family is one of the early auxin-responsive gene families and encodes short-lived proteins. It may play important 
roles in plant cell elongation. Recently, the functions of SAUR genes have become an important research topic. The putative functions of SAUR genes depend largely on the distribution of the proteins these genes encode. The subcellular locations of SAUR proteins were studied in recent years. Most of the proteins could be observed in the nucleus, cytoplasm or plasma membrane. The expression levels of most of the genes were up-regulated after auxin treatment (Kant et al. 2009; Chae et al. 2012; Spartz et al. 2012; Kong et al. 2013; Markakis et al. 2013; Li et al. 2015). Most studies demonstrated that SAUR proteins could promote cell elongation. The functions of SAUR genes were demonstrated in the process of cell elongation (Spartz et al. 2014). In our study, most PheSAUR genes were up-regulated after IAA treatment. Hence, PheSAUR genes may play similar roles in P. edulis.

\section{Acknowledgments}

This project was supported and funded by the National High Technology Research and Development Program of China (Grant No. 2013AA102607-4), the National Natural Science Foundation of China (Grant No. 31570673) and projects of basic research of International Center for Bamboo and Rattan (Grant No. 1632016003).

\section{References}

Abel, S. and Theologis, A. 1996. Early genes and auxin action. Plant Physiol. 111(1): 9. Available from http://www.plantphysiol.org/content/111/1/9.full.pdf [accessed 15 July 2014].

Ann, T., Kono, N., Kosemura, S., Yamahura, S. and Hasegawa, K. 1998. Isolation and characterization of an auxin-inducible SAUR gene from radish seedlings. Dna. Sequence. 9(5-6): 329-333. Available from http://www.tandfonline.com/doi/pdf/10.3109/10425179809008472 [accessed 23 July 2014].

Bailey, T. L., Williams, N., Misleh, C. and Li, W. W. 2006. MEME: discovering and analyzing DNA and protein sequence 
motifs. Nucleic. Acids. Res. 34(suppl 2): W369-W373. Version 4.11.2. Available from http://nar.oxfordjournals.org/content/34/suppl_2/W369.full.pdf+html [accessed 25 May 2016].

Chae, K., Isaacs, C. G., Reeves, P. H., Maloney, G. S., Muday, G. K., Nagpal, P. and Reed, J. W. 2012. Arabidopsis SMALL AUXIN UP RNA63 promotes hypocotyl and stamen filament elongation. The Plant Journal. 71(4): 684-697. Available from http://onlinelibrary.wiley.com/doi/10.1111/j.1365-313X.2012.05024.x/full [accessed 15 July 2014].

Chen, Y., Hao, X. and Cao, J. 2014. Small auxin upregulated RNA (SAUR) gene family in maize: Identification, evolution, and its phylogenetic comparison with Arabidopsis, rice, and sorghum. Journal of integrative plant biology. 56(2): 133-150. Available from http://onlinelibrary.wiley.com/doi/10.1111/jipb.12127/full [accessed 23 July 2014].

Fan, C., Ma, J., Guo, Q., Li, X., Wang, H. and Lu, M. 2013. Selection of reference genes for quantitative real-time PCR in bamboo (Phyllostachys edulis). PloS one. 8(2): e56573. Available from http://journals.plos.org/plosone/article?id=10.1371/journal.pone.0056573 [accessed 15 July 2014].

Fedorova, L. and Fedorov, A. 2003. Introns in gene evolution. Origin and Evolution of New Gene Functions. Edited by M. Long. Springer Netherlands, Dordrecht: pp. 123-131.

Gil, P., Liu, Y., Orbovic, V., Verkamp, E., Poff, K. L. and Green, P. J. 1994. Characterization of the auxin-inducible SAUR-ACl gene for use as a molecular genetic tool in Arabidopsis. Plant Physiol. 104(2): 777-784. Available from http://www.plantphysiol.org/content/104/2/777.full.pdf+html [accessed 19 July 2014].

Guilfoyle, T., Hagen, G., Li, Y., Ulmasov, T., Liu, Z., Strabala, T. and Gee, M. 1993. Auxin-regulated transcription. Functional Plant Biology. 20(5): 489-502. Available from http://www.publish.csiro.au/?paper=PP9930489 [accessed 19 July 2014].

Guo, A. Y., Zhu, Q. H. and Chen, X. 2007. GSDS:a gene structure display server. Yi chuan $=$ Hereditas / Zhongguo yi chuan xue hui bian ji. 29(8): 1023-1026. Version 1.0. Available from http://europepmc.org/abstract/med/17681935 [accessed 19 
July 2014].

Hagen, G. and Guilfoyle, T. 2002. Auxin-responsive gene expression: genes, promoters and regulatory factors. Plant Mol. Biol. 49(3-4): 373-385. Available from http://link.springer.com/article/10.1023/A:1015207114117 [accessed 15 July 2014].

Hou, K., Wu, W. and Gan, S.-S. 2013. SAUR36, a small auxin up RNA gene, is involved in the promotion of leaf senescence in Arabidopsis. Plant Physiol. 161(2): 1002-1009. Available from http://www.plantphysiol.org/content/161/2/1002.full [accessed 23 August 2014].

Jain, M., Kaur, N., Garg, R., Thakur, J. K., Tyagi, A. K. and Khurana, J. P. 2006a. Structure and expression analysis of early auxin-responsive $A u x / I A A$ gene family in rice (Oryza sativa). Functional \& Integrative Genomics. 6(1): 47-59. Available from http://link.springer.com/article/10.1007\%2Fs10142-005-0005-0 [accessed 23 August 2014].

Jain, M., Tyagi, A. K. and Khurana, J. P. 2006b. Genome-wide analysis, evolutionary expansion, and expression of early auxin-responsive SAUR gene family in rice (Oryza sativa). Genomics. 88(3): 360-371. Available from http://www.sciencedirect.com/science/article/pii/S0888754306001170 [accessed 14 July 2014].

Kant, S., Bi, Y.-M., Zhu, T. and Rothstein, S. J. 2009. SAUR39, a small auxin-up RNA gene, acts as a negative regulator of auxin synthesis and transport in rice. Plant Physiol. 151(2): 691-701. Available from http://www.plantphysiol.org/content/151/2/691.full.pdf+html?with-ds=yes [accessed 14 July 2014].

Kong, Y., Zhu, Y., Gao, C., She, W., Lin, W., Chen, Y., Han, N., Bian, H., Zhu, M. and Wang, J. 2013. Tissue-specific expression of SMALL AUXIN UP RNA41 differentially regulates cell expansion and root meristem patterning in Arabidopsis. Plant Cell Physiol. 54(4): 609-621. Available from http://pcp.oxfordjournals.org/content/54/4/609.short [accessed 4 March 2015].

Kuang, J.-F., Wu, J.-Y., Zhong, H.-Y., Li, C.-Q., Chen, J.-Y., Lu, W.-J. and Li, J.-G. 2012. Carbohydrate stress affecting fruitlet abscission and expression of genes related to auxin signal transduction pathway in litchi. International journal of 16 
molecular sciences. 13(12): 16084-16103. Available from http://www.mdpi.com/1422-0067/13/12/16084/htm [accessed 29 August 2014].

Lamesch, P., Berardini, T. Z., Li, D., Swarbreck, D., Wilks, C., Sasidharan, R., Muller, R., Dreher, K., Alexander, D. L., Garcia-Hernandez, M., Karthikeyan, A. S., Lee, C. H., Nelson, W. D., Ploetz, L., Singh, S., Wensel, A. and Huala, E. 2012. The Arabidopsis Information Resource (TAIR): improved gene annotation and new tools. Nucleic. Acids. Res. 40(D1): D1202-D1210. Version 10. Available from http://nar.oxfordjournals.org/content/40/D1/D1202.full.pdf+html [accessed 15 July 2014].

Larkin, M. A., Blackshields, G., Brown, N. P., Chenna, R., McGettigan, P. A., McWilliam, H., Valentin, F., Wallace, I. M., Wilm, A., Lopez, R., Thompson, J. D., Gibson, T. J. and Higgins, D. G. 2007. Clustal W and Clustal X version 2.0. $\begin{array}{llllll}\text { Bioinformatics. } & \mathbf{2 3}(21): & \text { 2947-2948. } & \text { Version } & \text { 2.1. } & \text { Available }\end{array}$ http://bioinformatics.oxfordjournals.org/content/23/21/2947.abstract [accessed 15 July 2014].

Lecharny, A., Boudet, N., Gy, I., Aubourg, S. and Kreis, M. 2003. Introns in, introns out in plant gene families: a genomic approach of the dynamics of gene structure. Journal of Structural and Functional Genomics. 3(1): 111-116. Available from http://dx.doi.org/10.1023/A:1022614001371 [accessed 29 August 2014].

Lescot, M., Déhais, P., Thijs, G., Marchal, K., Moreau, Y., Van de Peer, Y., Rouzé, P. and Rombauts, S. 2002. PlantCARE, a database of plant cis-acting regulatory elements and a portal to tools for in silico analysis of promoter sequences. Nucleic. Acids. Res. 30(1): 325-327. Version 5.5. Available from http://nar.oxfordjournals.org/content/30/1/325.abstract [accessed 28 August 2015].

Li, Z.-G., Chen, H.-W., Li, Q.-T., Tao, J.-J., Bian, X.-H., Ma, B., Zhang, W.-K., Chen, S.-Y. and Zhang, J.-S. 2015. Three SAUR proteins SAUR76, SAUR77 and SAUR78 promote plant growth in Arabidopsis. Scientific reports. 5. Available from http://www.nature.com/articles/srep12477 [accessed 28 August 2015]. 
Lin, J., He, X., Hu, Y., Kuang, T. and Ceulemans, R. 2002. Lignification and lignin heterogeneity for various age classes of bamboo (Phyllostachys pubescens) stems. Physiol. Plantarum. 114(2): 296-302. Available from http://onlinelibrary.wiley.com/doi/10.1034/j.1399-3054.2002.1140216.x/full [accessed 28 August 2015].

Marchler-Bauer, A., Derbyshire, M. K., Gonzales, N. R., Lu, S., Chitsaz, F., Geer, L. Y., Geer, R. C., He, J., Gwadz, M., Hurwitz, D. I., Lanczycki, C. J., Lu, F., Marchler, G. H., Song, J. S., Thanki, N., Wang, Z., Yamashita, R. A., Zhang, D., Zheng, C. and Bryant, S. H. 2014. CDD: NCBI's conserved domain database. Nucleic. Acids. Res. gku1221. Version 3.15. Available from http://nar.oxfordjournals.org/content/early/2014/11/20/nar.gku1221.abstract [accessed 15 July 2014].

Markakis, M. N., Boron, A. K., Van Loock, B., Saini, K., Cirera, S., Verbelen, J.-P. and Vissenberg, K. 2013. Characterization of a small auxin-up RNA (SAUR)-like gene involved in Arabidopsis thaliana development. PloS one. 8(11): e82596. Available from http://journals.plos.org/plosone/article/asset?id=10.1371\%2Fjournal.pone.0082596.PDF [accessed 14 July 2014].

Mascarenhas, D., Mettler, I. J., Pierce, D. A. and Lowe, H. W. 1990. Intron-mediated enhancement of heterologous gene expression in maize. Plant Mol. Biol. 15(6): 913-920. Available from http://link.springer.com/article/10.1007/BF00039430 [accessed 14 July 2014].

Murphy, R. and Alvin, K. 1992. Variation in fibre wall structure in bamboo. Iawa. J. 13(4): 403-410. http://booksandjournals.brillonline.com/content/journals/10.1163/22941932-90001296 [accessed 15 July 2014].

Newman, T. C., Ohme-Takagi, M., Taylor, C. B. and Green, P. J. 1993. DST sequences, highly conserved among plant SAUR genes, target reporter transcripts for rapid decay in tobacco. The Plant Cell. 5(6): 701-714. Available from http://www.plantcell.org/content/5/6/701.full.pdf+html [accessed 14 July 2014].

Park, J. E., Kim, Y. S., Yoon, H. K. and Park, C. M. 2007. Functional characterization of a small auxin-up RNA gene in apical hook development in Arabidopsis. Plant Sci. 172(1): 150-157. Available from 18 
http://www.sciencedirect.com/science/article/pii/S0168945206002342 [accessed 15 July 2014].

Parra, G., Bradnam, K., Rose, A. B. and Korf, I. 2011. Comparative and functional analysis of intron-mediated enhancement signals reveals conserved features among plants. Nucleic. Acids. Res. 39(13): 5328-5337. Version 2.0. Available from http://nar.oxfordjournals.org/content/39/13/5328.full.pdf + html [accessed 15 July 2014].

Peng, Z., Lu, T., Li, L., Liu, X., Gao, Z., Hu, T., Yang, X., Feng, Q., Guan, J. and Weng, Q. 2010. Genome-wide characterization of the biggest grass, bamboo, based on 10,608 putative full-length cDNA sequences. BMC plant biology. 10(1): 116. Available from http://bmcplantbiol.biomedcentral.com/articles/10.1186/1471-2229-10-116 [accessed 14 July 2014].

Peng, Z., Lu, Y., Li, L., Zhao, Q., Feng, Q., Gao, Z., Lu, H., Hu, T., Yao, N. and Liu, K. 2013a. The draft genome of the fast-growing non-timber forest species moso bamboo (Phyllostachys heterocycla). Nat. Genet. 45(4): 456-461. Available from http://www.nature.com/ng/journal/v45/n4/pdf/ng.2569.pdf [accessed 6 July 2014].

Peng, Z., Zhang, C., Zhang, Y., Hu, T., Mu, S., Li, X. and Gao, J. 2013b. Transcriptome sequencing and analysis of the fast growing shoots of moso bamboo (Phyllostachys edulis). PloS one. 8(11): e78944. Available from http://journals.plos.org/plosone/article?id=10.1371/journal.pone.0078944 [accessed 26 July 2014].

Remington, D. L., Vision, T. J., Guilfoyle, T. J. and Reed, J. W. 2004. Contrasting modes of diversification in the $A u x / I A A$ and ARF gene families. Plant Physiol. 135(3): 1738-1752. Available from http://www.plantphysiol.org/content/135/3/1738 [accessed 14 July 2014].

Ren, H. and Gray, W. M. 2015. SAUR Proteins as Effectors of Hormonal and Environmental Signals in Plant Growth. Molecular Plant. 8(8): 1153-1164. Available from http://www.cell.com/molecular-plant/pdf/S1674-2052(15)00236-1.pdf [accessed 4 March 2016].

Rensing, S. A., Lang, D., Zimmer, A. D., Terry, A., Salamov, A., Shapiro, H., Nishiyama, T., Perroud, P.-F., Lindquist, E. A. 19 
and Kamisugi, Y. 2008. The Physcomitrella genome reveals evolutionary insights into the conquest of land by plants.

Science. 319(5859): 64-69. Available from http://science.sciencemag.org/content/319/5859/64.full.pdf + html [accessed 14

July 2014].

Roy, S. W. and Gilbert, W. 2006. The evolution of spliceosomal introns: patterns, puzzles and progress. Nat. Rev. Genet. 7(3):

211-221. Available from http://www.nature.com/nrg/journal/v7/n3/abs/nrg1807.html [accessed 14 July 2014].

Spartz, A. K., Lee, S. H., Wenger, J. P., Gonzalez, N., Itoh, H., Inzé, D., Peer, W. A., Murphy, A. S., Overvoorde, P. J. and

Gray, W. M. 2012. The SAUR19 subfamily of SMALL AUXIN UP RNA genes promote cell expansion. The Plant Journal.

70(6): 978-990. Available from http://onlinelibrary.wiley.com/doi/10.1111/j.1365-313X.2012.04946.x/full [accessed 14 July

2014].

Spartz, A. K., Ren, H., Park, M. Y., Grandt, K. N., Lee, S. H., Murphy, A. S., Sussman, M. R., Overvoorde, P. J. and Gray, W.

M. 2014. SAUR inhibition of PP2C-D phosphatases activates plasma membrane H+-ATPases to promote cell expansion in

Arabidopsis. The Plant Cell. 26(5): 2129-2142. Available from http://www.plantcell.org/content/26/5/2129.full [accessed 4

March 2015].

Sullivan, M. L. and Green, P. J. 1996. Mutational analysis of the DST element in tobacco cells and transgenic plants: identification of residues critical for mRNA instability. RNA. 2(4): 308-315. Available from http://rnajournal.cshlp.org/content/2/4/308.full.pdf+html [accessed 14 July 2014].

Tamura, K., Stecher, G., Peterson, D., Filipski, A. and Kumar, S. 2013. MEGA6: Molecular Evolutionary Genetics Analysis Version 6.0. Mol. Biol. Evol. 30(12): 2725-2729. Version 6.0. Available from http://mbe.oxfordjournals.org/content/30/12/2725.full.pdf + html [accessed 23 August 2014].

Tatsuki, M., Nakajima, N., Fujii, H., Shimada, T., Nakano, M., Hayashi, K.-i., Hayama, H., Yoshioka, H. and Nakamura, Y. 2013. Increased levels of IAA are required for system 2 ethylene synthesis causing fruit softening in peach (Prunus persica L. 
Batsch). J. Exp. Bot. 64(4): 1049-1059. Available from http://jxb.oxfordjournals.org/content/64/4/1049.full.pdf+html [accessed 14 July 2014].

Untergasser, A., Cutcutache, I., Koressaar, T., Ye, J., Faircloth, B. C., Remm, M. and Rozen, S. G. 2012. Primer3-new capabilities and interfaces. Nucleic. Acids. Res. 40(15): e115. Version 4.0.0. Available from http://nar.oxfordjournals.org/content/40/15/e115.full.pdf + html [accessed 25 April 2015].

Kawahara, Y., Bastide, M. D. L., Hamilton, J. P., Kanamori, H., Mccombie, W. R., Shu, O., Schwartz, D. C., Tanaka, T., Wu, J. and Zhou, S. 2013. Improvement of the Oryza sativa Nipponbare reference genome using next generation sequence and optical map data. $\quad$ Rice. 6(1): 1-10. $\quad$ Version $7 . \quad$ Available from http://thericejournal.springeropen.com/articles/10.1186/1939-8433-6-4 [accessed 14 July 2014].

Wang, B., Du, Q., Yang, X. and Zhang, D. 2014. Identification and characterization of nuclear genes involved in photosynthesis in Populus. BMC plant biology. 14(1): 81. Available from http://bmcplantbiol.biomedcentral.com/articles/10.1186/1471-2229-14-81 [accessed 14 July 2014].

Wang, S., Bai, Y., Shen, C., Wu, Y., Zhang, S., Jiang, D., Guilfoyle, T. J., Chen, M. and Qi, Y. 2010. Auxin-related gene families in abiotic stress response in Sorghum bicolor. Functional \& integrative genomics. 10(4): 533-546. Available from http://link.springer.com/article/10.1007/s10142-010-0174-3 [accessed 14 July 2014].

Watillon, B., Kettmann, R., Arredouani, A., Hecquet, J.-F., Boxus, P. and Burny, A. 1998. Apple messenger RNAs related to bacterial lignostilbene dioxygenase and plant SAUR genes are preferentially expressed in flowers. Plant Mol. Biol. 36(6): 909-915. Available from http://link.springer.com/article/10.1023/A:1005914506110 [accessed 15 July 2014].

Wu, J., Liu, S., He, Y., Guan, X., Zhu, X., Cheng, L., Wang, J. and Lu, G. 2012. Genome-wide analysis of SAUR gene family in $\quad$ Solanaceae $\quad$ species. $\quad$ Gene. $\quad \mathbf{5 0 9}(1): \quad 38-50 . \quad$ Available $\quad$ from http://www.sciencedirect.com/science/article/pii/S0378111912009511 [accessed 15 July 2014]. 
Xie, R., Dong, C., Ma, Y., Deng, L., He, S., Yi, S., Lv, Q. and Zheng, Y. 2015. Comprehensive analysis of SAUR gene family in citrus and its transcriptional correlation with fruitlet drop from abscission zone A. Functional \& integrative genomics. 15(6): 729-740. Available from http://link.springer.com/article/10.1007/s10142-015-0450-3 [accessed 7 January 2016].

Yamamoto, K. T., Mori, H. and Imaseki, H. 1992. cDNA cloning of indole-3-acetic acid-regulated genes: Aux22 and SAUR from mung bean (Vigna radiata) hypocotyl tissue. Plant Cell Physiol. 33(1): 93-97. Available from http://pcp.oxfordjournals.org/content/33/1/93 [accessed 15 July 2014].

Yang, T. and Poovaiah, B. 2000. Molecular and biochemical evidence for the involvement of calcium/calmodulin in auxin action. J. Biol. Chem. 275(5): 3137-3143. Available from http://www.jbc.org/content/275/5/3137.full.pdf [accessed 15 July 2014].

Yang, X., Zhang, X., Yuan, D., Jin, F., Zhang, Y. and Xu, J. 2012. Transcript profiling reveals complex auxin signalling pathway and transcription regulation involved in dedifferentiation and redifferentiation during somatic embryogenesis in

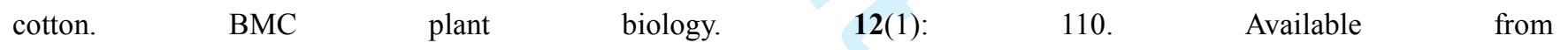
https://bmcplantbiol.biomedcentral.com/articles/10.1186/1471-2229-12-110 [accessed 15 July 2014].

Yu, C.-S., Lin, C.-J. L. and Hwang, J.-K. 2004. Predicting subcellular localization of proteins for Gram-negative bacteria by support vector machines based on nopeptide compositions. Protein Sci. 13(5): 1402-1406. Version 2.5. Available from http://onlinelibrary.wiley.com/doi/10.1110/ps.03479604/epdf [accessed 17 August 2014].

Zhao, H., Peng, Z., Fei, B., Li, L., Hu, T., Gao, Z. and Jiang, Z. 2014. BambooGDB: a bamboo genome database with functional annotation and an analysis platform. Database. bau006. Version 1 . Available from http://database.oxfordjournals.org/content/2014/bau006.full.pdf+html [accessed 15 July 2014].

Zurek, D. M., Rayle, D. L., McMorris, T. C. and Clouse, S. D. 1994. Investigation of gene expression, growth kinetics, and wall extensibility during brassinosteroid-regulated stem elongation. Plant Physiol. 104(2): 505-513. Available from 
http://www.plantphysiol.org/content/104/2/505.full.pdf+html [accessed 15 July 2014]. 
Fig. 1. Phylogenetic tree and gene structure of PheSAUR genes. A, Neighbor-joining method and MEGA 6.0 software were used for phylogenetic analysis of PheSAURs with their amino acid sequences. A showed the relationship of all the 38 PheSAUR genes. All the PheSAUR genes could be divided into 4 subgroups. Bootstrap value (above 50\%) supports from 1000 replicates are indicated at each branch. B, Gene structures of all the PheSAUR genes were showed. The green color parts represent exons and the black lines represent introns.

Fig. 2. Phylogenetic relationship of PheSAUR, AtSAUR and OsSAUR proteins. Neighbor-joining method and MEGA 6.0 software were used for phylogenetic analysis of SAUR proteins from Phyllostachys edulis (PheSAUR), Arabidopsis thaliana (AtSAUR) and Oryza sativa (OsSAUR). In total, 38 PheSAUR, 55 OsSAUR and 79 AtSAUR proteins were analyzed and could be divided into 5 subgroups. PheSAUR, AtSAUR and OsSAUR proteins were highlighted in Red circles, blue triangles and green boxes respectively. Bootstrap value (above 50\%) supports from 1000 replicates are indicated at each branch.

Fig. 3. Heat map of the FPKM values of PheSAUR genes. Top internodes were collected at the heights of $0.1,0.5$, 1, 3, 6, 9, 12 and 15 meters (control). Fragments Per Kilobase of exon model per Million mapped reads (FPKM) was used to build the heat map. The color scale is shown at the right of the heat map.

Fig. 4. Heat map of the real-time quantitative PCR (qRT-PCR) analysis results of PheSAUR genes in leaves, stems and roots under IAA treatments. Leaf, stem and root were used for analysis and the materials were collected at $0,1,3$ and 5 hours. The expression levels of PheSAUR genes are presented using fold change values transformed to log2 format compared to controls. Expression levels of leave, stems and roots at $0 \mathrm{~h}$ were unified to 1 . The color scale is shown at the right of the heat map. 
Fig. 5. Relative expression levels of PheSAURs in leaves, stems and roots in $P$. edulis seedlings. Leaves, stems and roots in P. edulis seedlings were collected and quantitative real-time PCR was used for analysis.

Fig. S1. Conserved consensus motifs identified in PheSAUR, OsSAUR and AtSAUR proteins. Five conserved consensus motifs in PheSAUR, OsSAUR and AtSAUR proteins (172 proteins) were found by MEME. The symbol heights represent the relative frequency of each residue. The numbers of sites and e-value for each motif are also shown. 
Table 1 Overview of PheSAUR genes in moso bamboo

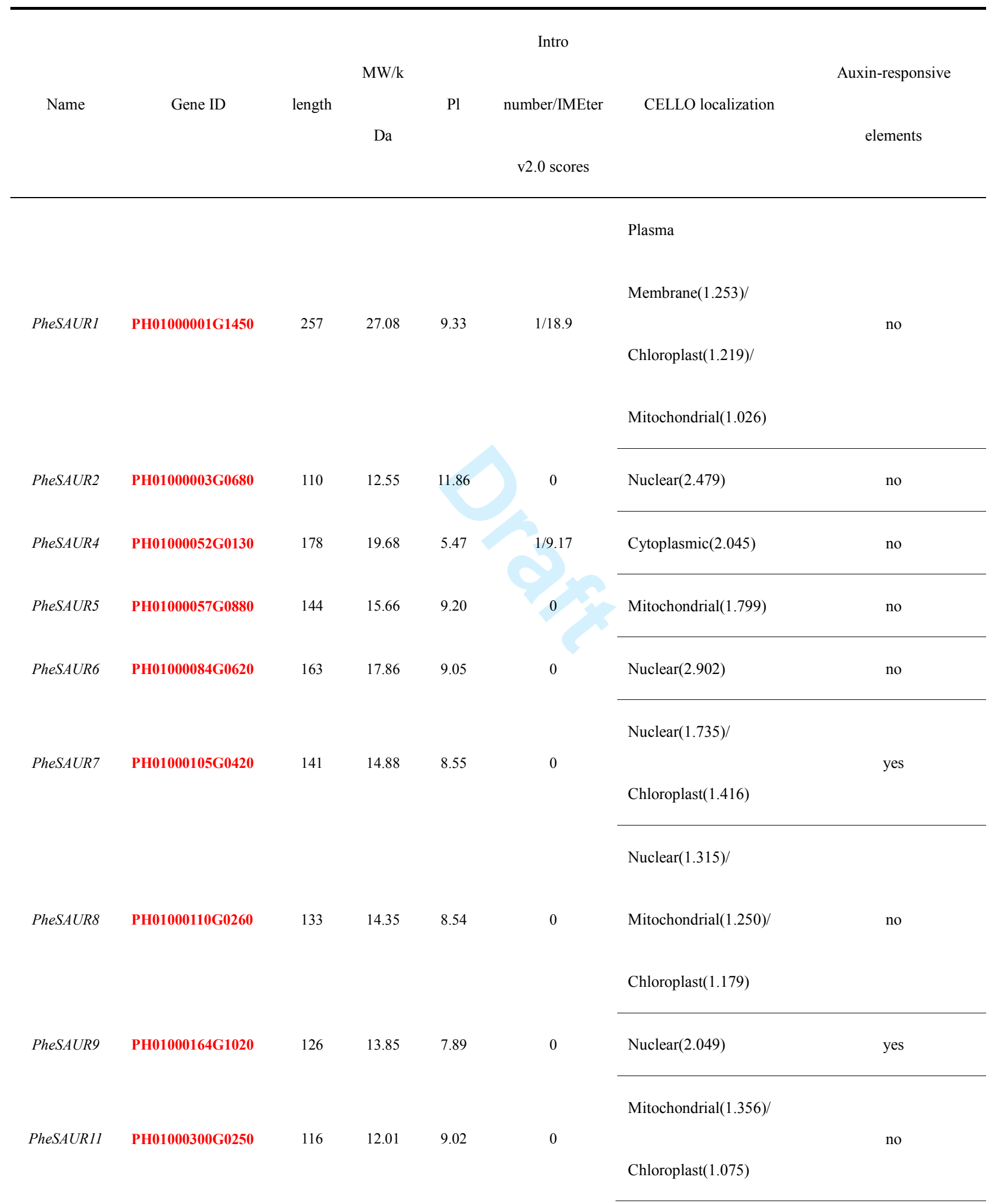




\begin{tabular}{|c|c|c|c|c|c|c|c|}
\hline PheSAUR12 & PH01000300G0310 & 94 & 10.02 & 6.28 & 0 & Cytoplasmic(1.751) & yes \\
\hline PheSAUR13 & PH01000338G0730 & 116 & 11.96 & 9.16 & 0 & Mitochondrial(1.263) & no \\
\hline PheSAUR14 & PH01000402G1010 & 83 & 8.88 & 8.55 & 0 & Chloroplast(1.875) & no \\
\hline \multirow[t]{2}{*}{ PheSAUR15 } & PH01000407G0060 & 120 & 12.98 & 8.59 & 0 & Nuclear(1.812) & no \\
\hline & & & & & & Mitochondrial(1.481)/ & \\
\hline \multirow[t]{3}{*}{ PheSAUR16 } & PH01000548G0100 & 121 & 13.91 & 8.80 & 0 & Cytoplasmic(1.388)/ & yes \\
\hline & & & & & & Nuclear(1.033) & \\
\hline & & & & & & Nuclear(1.382)/ & \\
\hline \multirow[t]{3}{*}{ PheSAUR17 } & PH01001308G0070 & 116 & 13.03 & 9.26 & 0 & Mitochondrial(1.205)/ & no \\
\hline & & & & & & Cytoplasmic(1.062) & \\
\hline & & & & & & Nuclear(1.691)/ & \\
\hline \multirow[t]{2}{*}{ PheSAUR18 } & PH01001346G0370 & 160 & 17.49 & 8.75 & 0 & & yes \\
\hline & & & & & & Mitochondrial(1.498)/ & \\
\hline \multirow[t]{2}{*}{ PheSAUR19 } & PH01001542G0200 & 109 & 11.79 & 9.22 & 0 & & no \\
\hline & & & & & & Nuclear(1.036) & \\
\hline PheSAUR20 & PH01001832G0020 & 154 & 17.28 & 8.81 & 0 & Mitochondrial(1.312) & no \\
\hline PheSAUR21 & PH01001866G0310 & 144 & 16.04 & 8.83 & 0 & Nuclear(1.641)/ & yes \\
\hline \multirow[t]{2}{*}{ PheSAUR22 } & PH01002017G0200 & 154 & 17.23 & 11.91 & 0 & Nuclear(3.237) & no \\
\hline & & & & & & Mitochondrial(1.489)/ & \\
\hline \multirow[t]{2}{*}{ PheSAUR23 } & PH01002025G0060 & 147 & 16.54 & 9.96 & 0 & & yes \\
\hline & & & & & & Nuclear(1.474)/ & \\
\hline PheSAUR24 & PH01002316G0030 & 179 & 18.70 & 9.33 & 0 & Nuclear(1.534)/ & yes \\
\hline
\end{tabular}




\begin{tabular}{|c|c|c|c|c|c|c|c|}
\hline PheSAUR25 & PH01002921G0180 & 125 & 13.75 & 6.10 & 0 & & no \\
\hline PheSAUR26 & PH01002921G0190 & 140 & 15.50 & 8.92 & 0 & Mitochondrial(1.700) & yes \\
\hline PheSAUR27 & PH01002921G0250 & 145 & 16.28 & 7.64 & 0 & Mitochondrial(1.237) & yes \\
\hline \multirow[t]{2}{*}{ PheSAUR28 } & PH01003140G0110 & 102 & 11.02 & 7.77 & 0 & Mitochondrial(2.099) & yes \\
\hline & & & & & & Cytoplasmic(1.762)/ & \\
\hline \multirow[t]{3}{*}{ PheSAUR29 } & PH01003399G0150 & 113 & 12.15 & 9.62 & 0 & & no \\
\hline & & & & & & Mitochondrial(1.269) & \\
\hline & & & & & & Nuclear(1.293)/ & \\
\hline \multirow[t]{2}{*}{ PheSAUR31 } & PH01003710G0040 & 155 & 16.01 & 8.52 & 0 & Mitochondrial(1.280)/ & no \\
\hline & & & & & & Chloroplast(1.088) & \\
\hline PheSAUR32 & PH01004171G0020 & 129 & 14.51 & 5.91 & $1 / 21.5$ & Cytoplasmic(1.772) & no \\
\hline PheSAUR34 & PH01004534G0100 & 147 & 15.67 & 8.24 & 0 & Chloroplast(2.619) & yes \\
\hline \multirow[t]{2}{*}{ PheSAUR35 } & PH01004534G0130 & 134 & 14.95 & 6.81 & 0 & /Nuclear(1.331) & no \\
\hline & & & & & & Mitochondrial(1.560)/ & \\
\hline \multirow[t]{2}{*}{ PheSAUR36 } & PH01006019G0010 & 138 & 15.10 & 6.37 & 0 & Nuclear(1.267)/ & yes \\
\hline & & & & & & Cytoplasmic(1.110) & \\
\hline \multirow[t]{2}{*}{ PheSAUR37 } & PH01006114G0030 & 246 & 27.20 & 11.05 & $2 / 17.12$ & Mitochondrial(2.541) & yes \\
\hline & & & & & & Nuclear(1.494)/ & \\
\hline \multirow[t]{2}{*}{ PheSAUR38 } & PH01015485G0020 & 95 & 10.68 & 7.62 & 0 & Chloroplast(1.042)/ & yes \\
\hline & & & & & & Cytoplasmic(1.039) & \\
\hline PheSAUR41 & PH01000012G1930 & 109 & 12.22 & 7.23 & 0 & Mitochondrial(1.365)/ & yes \\
\hline
\end{tabular}




\begin{tabular}{|c|c|c|c|c|c|c|c|}
\hline \multirow[b]{2}{*}{ PheSAUR42 } & \multirow[b]{2}{*}{ PH01000114G0400 } & \multirow[b]{2}{*}{1148} & \multirow[b]{2}{*}{128.04} & \multirow[b]{2}{*}{6.59} & \multirow[b]{2}{*}{$18 / 13.39$} & \multicolumn{2}{|l|}{ Nuclear(1.195) } \\
\hline & & & & & & Nuclear(2.750) & no \\
\hline \multirow{3}{*}{ PheSAUR43 } & \multirow{3}{*}{ PH01000345G0270 } & \multirow{3}{*}{171} & \multirow{3}{*}{19.44} & & \multirow{3}{*}{$1 / 23.69$} & Plasma & \multirow{3}{*}{ yes } \\
\hline & & & & 7.17 & & Membrane(1.236)/ & \\
\hline & & & & & & Mitochondrial(1.108) & \\
\hline \multirow{3}{*}{ PheSAUR44 } & \multirow{3}{*}{ PH01002861G0060 } & \multirow{3}{*}{112} & \multirow{3}{*}{12.54} & & & Nuclear(1.350)/ & \multirow{3}{*}{ no } \\
\hline & & & & 6.37 & 0 & Cytoplasmic(1.190)/ & \\
\hline & & & & & & Mitochondrial(1.114) & \\
\hline
\end{tabular}

Note: length represent the amino acid sequences of PheSAUR proteins.

MW (molecular weight) represents the predicted weights of PheSAUR proteins.

Pl represents the predicted isoelectric point of PheSAUR proteins. 


\section{A}

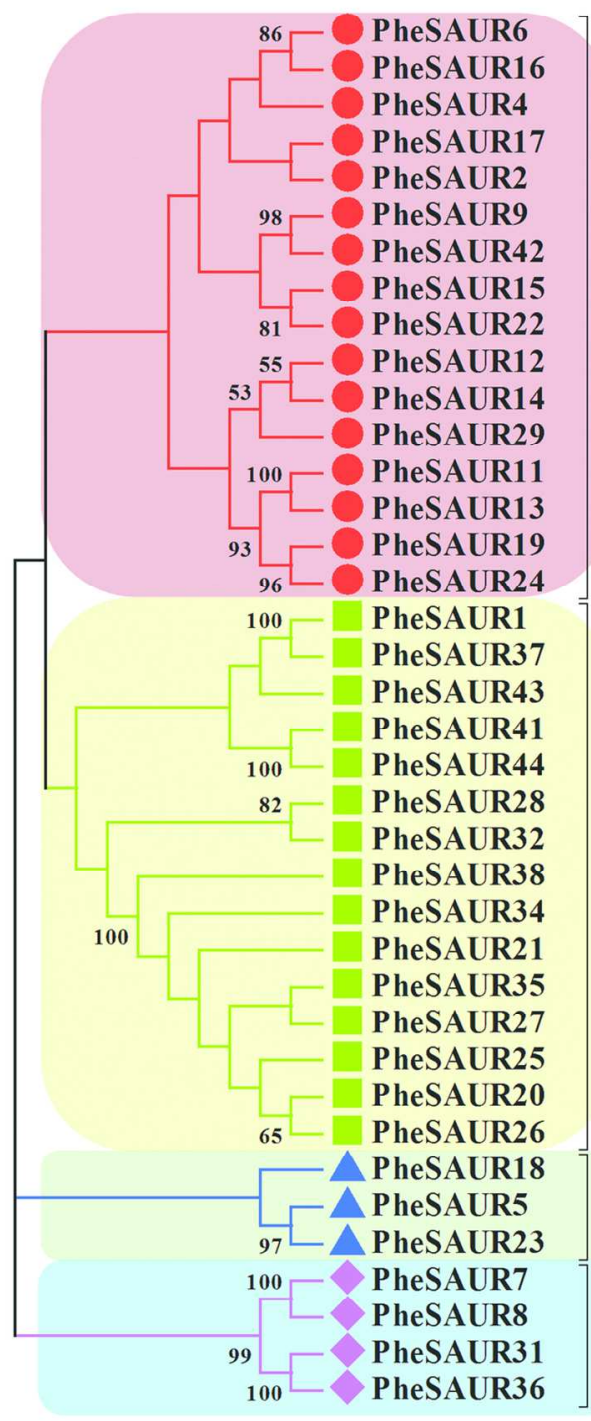

B

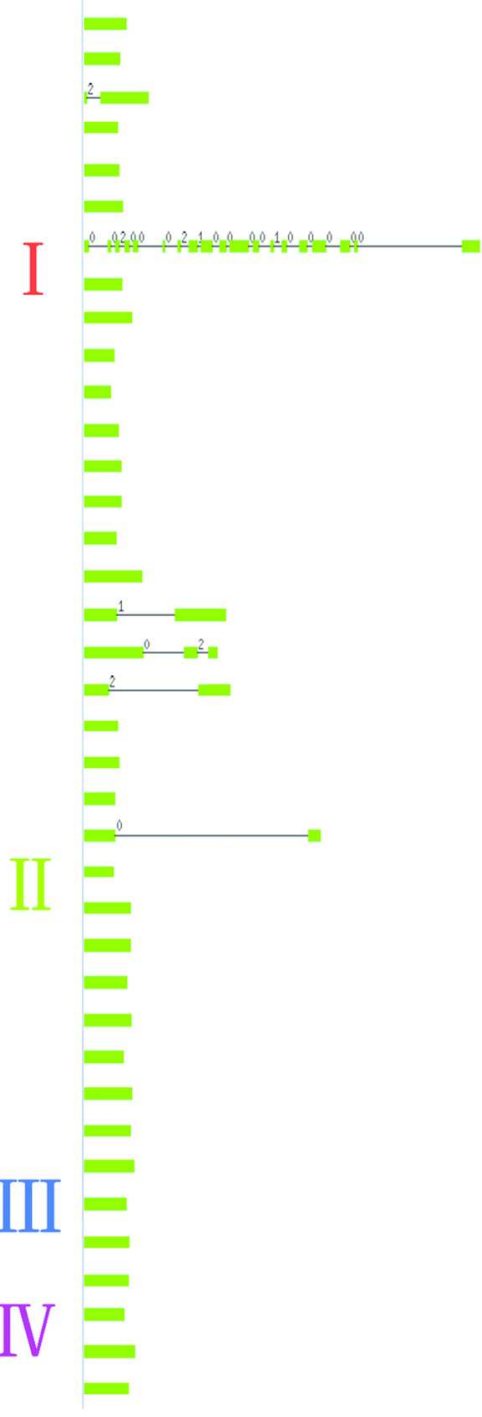

Fig. 1. Phylogenetic tree and gene structure of PheSAUR genes. A, Neighbor-joining method and MEGA 6.0 software were used for phylogenetic analysis of PheSAURs with their amino acid sequences. A showed the relationship of all the 38 PheSAUR genes. All the PheSAUR genes could be divided into 4 subgroups. Bootstrap value (above 50\%) supports from 1000 replicates are indicated at each branch. B, Gene structures of all the PheSAUR genes were showed. The green color parts represent exons and the black lines represent introns.

Fig. 1

$112 \times 147 \mathrm{~mm}(300 \times 300 \mathrm{DPI})$ 


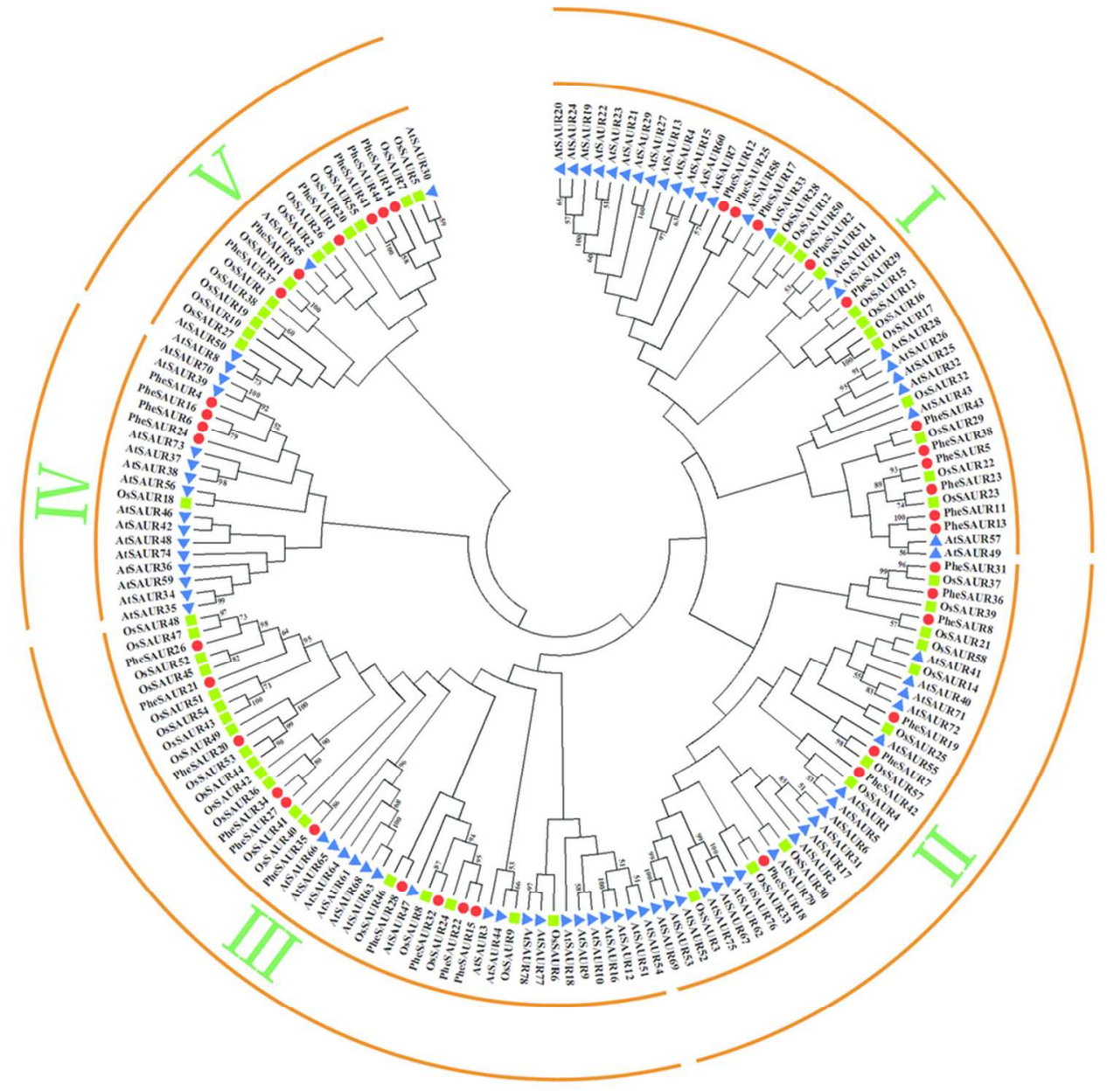

Fig. 2. Phylogenetic relationship of PheSAUR, AtSAUR and OsSAUR proteins. Neighbor-joining method and MEGA 6.0 software were used for phylogenetic analysis of SAUR proteins from Phyllostachys edulis (PheSAUR), Arabidopsis thaliana (AtSAUR) and Oryza sativa (OsSAUR). In total, 38 PheSAUR, 55 OsSAUR and 79 AtSAUR proteins were analyzed and could be divided into 5 subgroups. PheSAUR, AtSAUR and OsSAUR proteins were highlighted in Red circles, blue triangles and green boxes respectively. Bootstrap value (above $50 \%$ ) supports from 1000 replicates are indicated at each branch.

Fig. 2

$86 \times 87 \mathrm{~mm}(300 \times 300$ DPI $)$ 


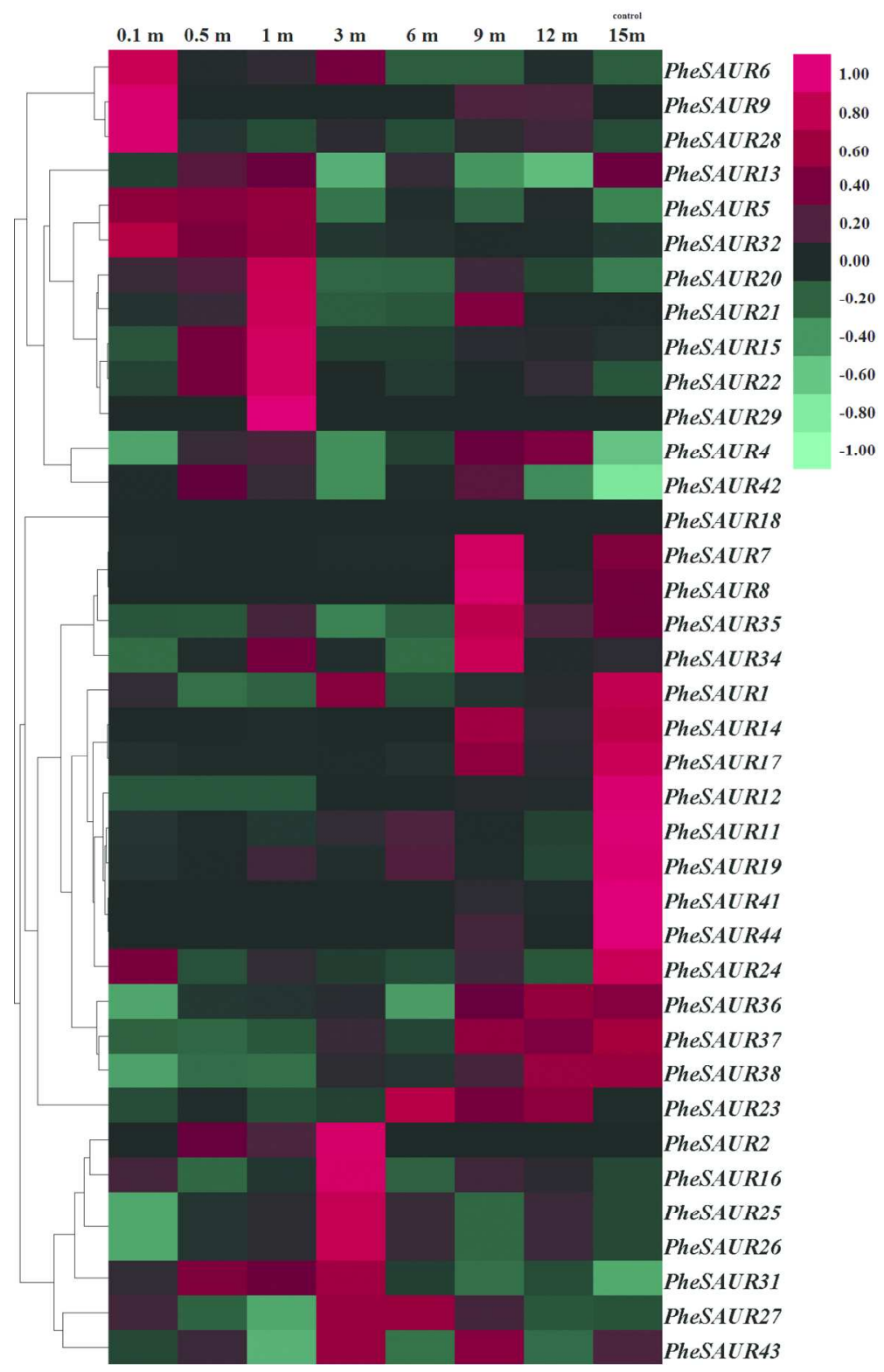

Fig. 3. Heat map of the FPKM values of PheSAUR genes. Top internodes were collected at the heights of 0.1 , $0.5,1,3,6,9,12$ and 15 meters (control). Fragments Per Kilobase of exon model per Million mapped reads (FPKM) was used to build the heat map. The color scale is shown at the right of the heat map.

Fig. 3

$131 \times 201 \mathrm{~mm}(300 \times 300 \mathrm{DPI})$ 


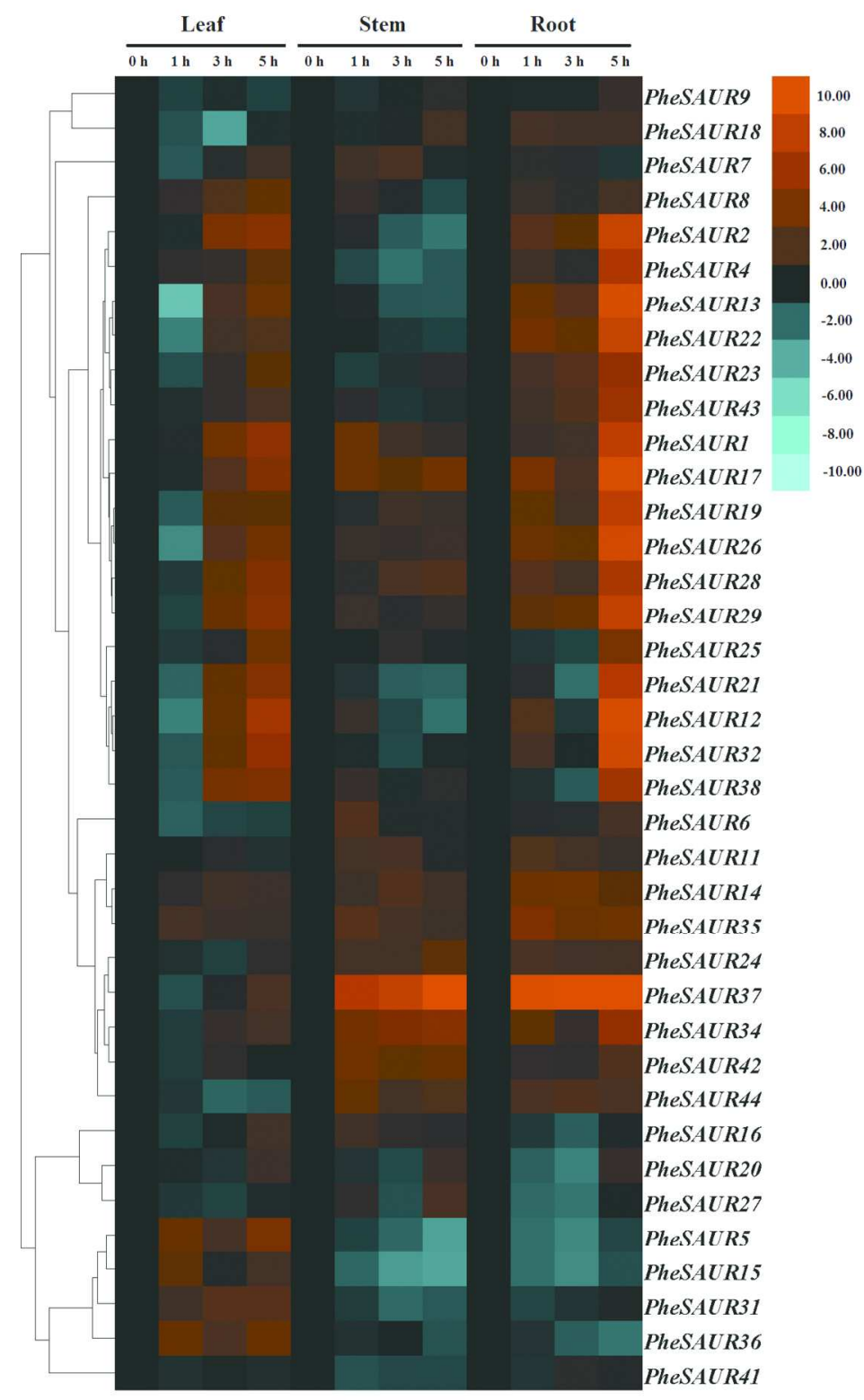

Fig. 4. Heat map of the real-time quantitative PCR (qRT-PCR) analysis results of PheSAUR genes in leaves, stems and roots under IAA treatments. Leaf, stem and root were used for analysis and the materials were collected at $0,1,3$ and 5 hours. The expression levels of PheSAUR genes are presented using fold change values transformed to $\log 2$ format compared to controls. Expression levels of leave, stems and roots at $0 \mathrm{~h}$ were unified to 1 . The color scale is shown at the right of the heat map.

Fig. 4

$141 \times 233 \mathrm{~mm}(300 \times 300$ DPI $)$ 


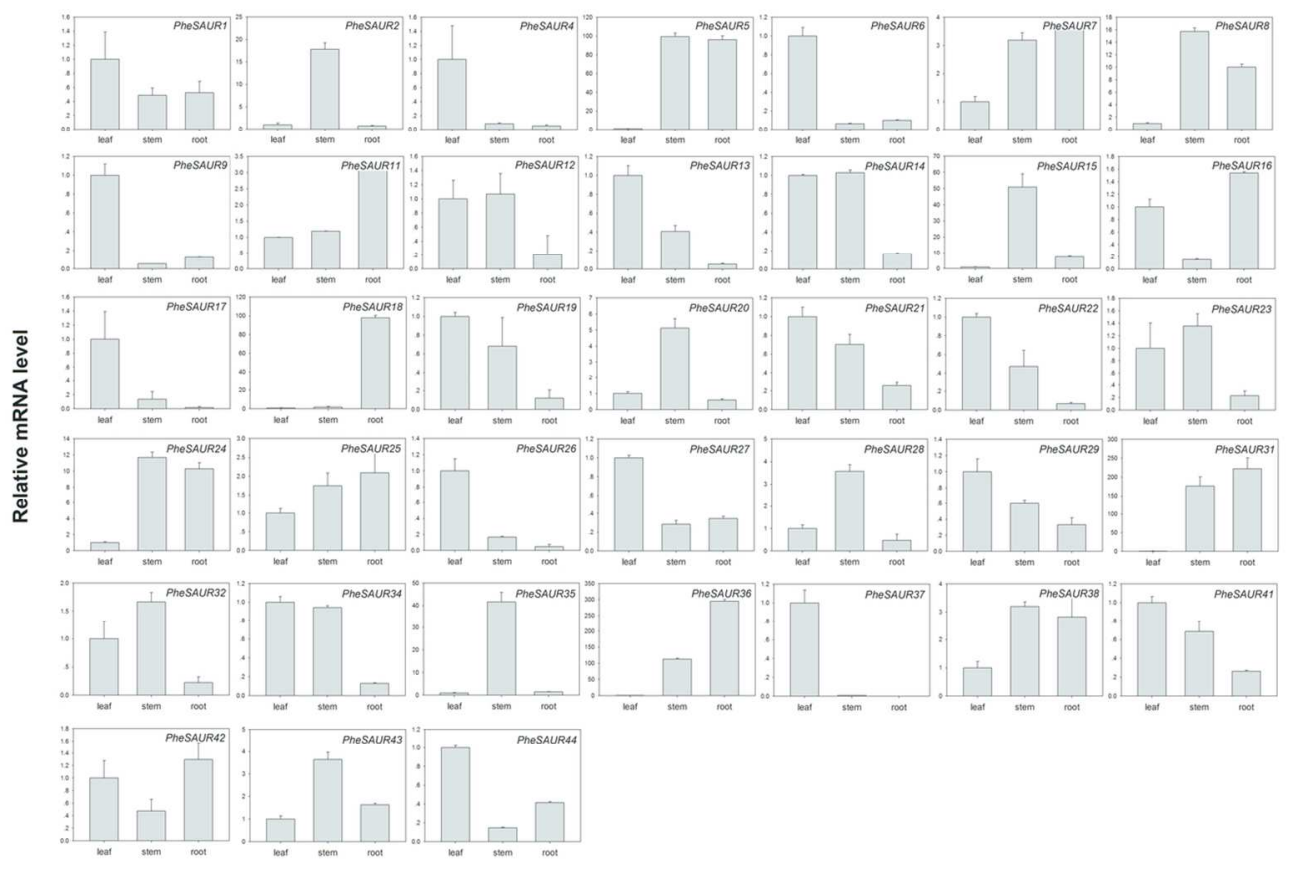

Fig. 5. Relative expression levels of PheSAURs in leaves, stems and roots in P. edulis seedlings. Leaves, stems and roots in P. edulis seedlings were collected and quantitative real-time PCR was used for analysis.

Fig. 5

$56 \times 37 \mathrm{~mm}(600 \times 600 \mathrm{DPI})$ 


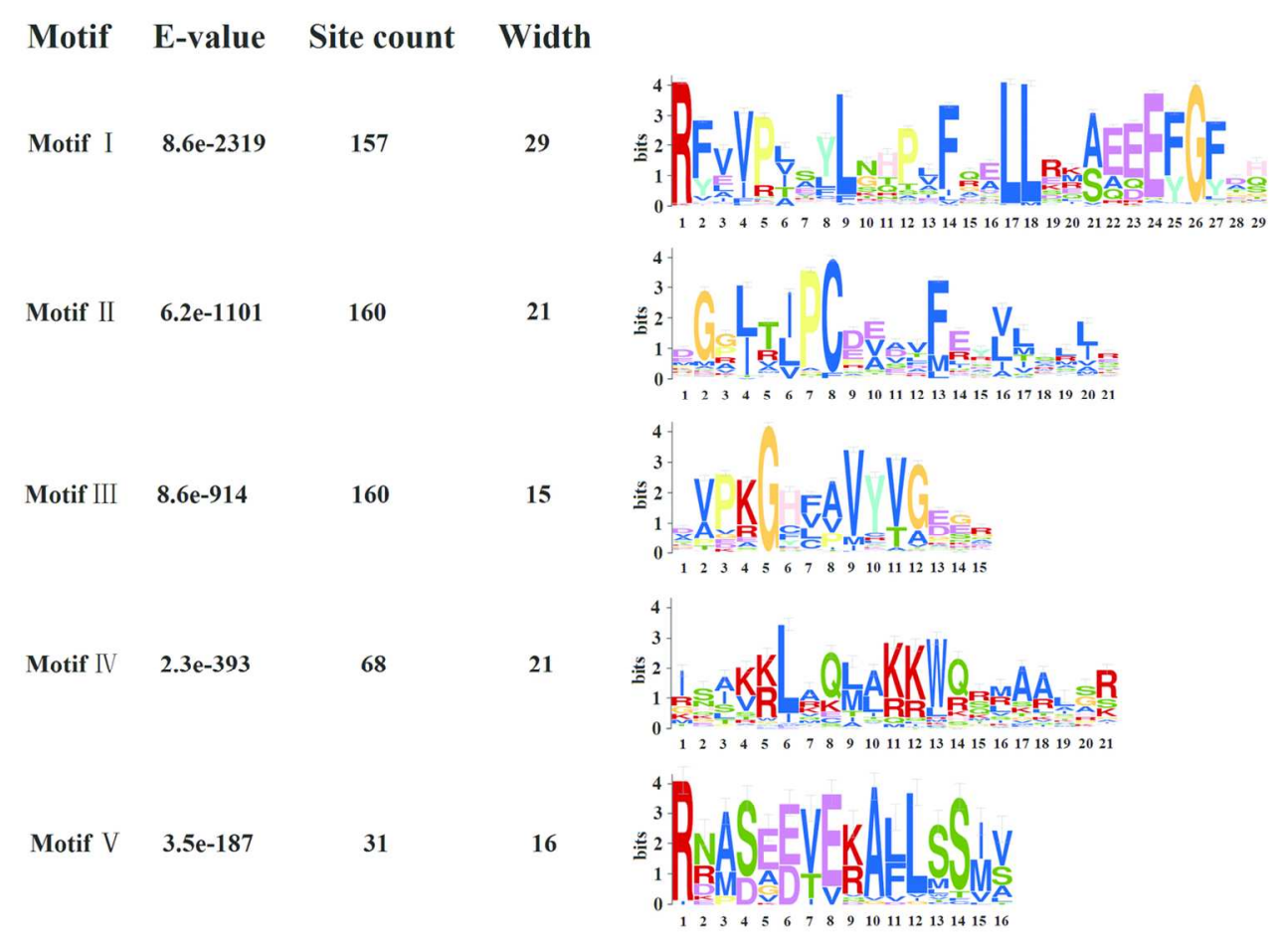

$62 \times 45 \mathrm{~mm}(600 \times 600 \mathrm{DPI})$ 
Table S1 The length of upstream and downstream untranslated regions

\begin{tabular}{|c|c|c|c|}
\hline \multirow{3}{*}{ Name } & \multirow{3}{*}{ Gene ID } & \multirow{3}{*}{$\begin{array}{c}\text { length of upstream } \\
\text { UTR (bp) }\end{array}$} & \multirow{3}{*}{$\begin{array}{c}\text { length of downstream } \\
\text { UTR (bp) }\end{array}$} \\
\hline & & & \\
\hline & & & \\
\hline PheSAUR1 & PH01000001G1450 & 141 & 614 \\
\hline PheSAUR2 & PH01000003G0680 & 112 & 207 \\
\hline PheSAUR4 & PH01000052G0130 & 1276 & 835 \\
\hline PheSAUR5 & PH01000057G0880 & 133 & 411 \\
\hline PheSAUR6 & PH01000084G0620 & 81 & 242 \\
\hline PheSAUR7 & PH01000105G0420 & 108 & 381 \\
\hline PheSAUR8 & PH01000110G0260 & 223 & 749 \\
\hline PheSAUR9 & PH01000164G1020 & 333 & 508 \\
\hline PheSAUR11 & PH01000300G0250 & 95 & 457 \\
\hline PheSAUR12 & PH01000300G0310 & 121 & 887 \\
\hline PheSAUR13 & PH01000338G0730 & 102 & 865 \\
\hline PheSAUR14 & PH01000402G1010 & 112 & 79 \\
\hline PheSAUR 15 & PH01000407G0060 & 104 & 107 \\
\hline PheSAUR16 & PH01000548G0100 & 90 & 476 \\
\hline PheSAUR17 & PH01001308G0070 & 151 & 898 \\
\hline PheSAUR 18 & PH01001346G0370 & 480 & 861 \\
\hline PheSAUR19 & PH01001542G0200 & 127 & 915 \\
\hline PheSAUR20 & PH01001832G0020 & 78 & 172 \\
\hline
\end{tabular}




\begin{tabular}{|c|c|c|c|}
\hline PheSAUR 21 & PH01001866G0310 & 78 & 1658 \\
\hline PheSAUR22 & PH01002017G0200 & 69 & 57 \\
\hline PheSAUR23 & PH01002025G0060 & 105 & 208 \\
\hline PheSAUR24 & PH01002316G0030 & 270 & 417 \\
\hline PheSAUR25 & PH01002921G0180 & 166 & 473 \\
\hline PheSAUR26 & PH01002921G0190 & 428 & 466 \\
\hline PheSAUR27 & PH01002921G0250 & 67 & 84 \\
\hline PheSAUR28 & PH01003140G0110 & 79 & 378 \\
\hline PheSAUR29 & PH01003399G0150 & 1687 & 642 \\
\hline PheSAUR 31 & PH01003710G0040 & 102 & 736 \\
\hline PheSAUR32 & PH01004171G0020 & 137 & 533 \\
\hline PheSAUR34 & PH01004534G0100 & 109 & 157 \\
\hline PheSAUR35 & PH01004534G0130 & 151 & 659 \\
\hline PheSAUR36 & PH01006019G0010 & 97 & 368 \\
\hline PheSAUR37 & PH01006114G0030 & 568 & 44 \\
\hline PheSAUR38 & PH01015485G0020 & 195 & 132 \\
\hline PheSAUR41 & PH01000012G1930 & 315 & 977 \\
\hline PheSAUR42 & PH01000114G0400 & 625 & 295 \\
\hline PheSAUR43 & PH01000345G0270 & 3291 & 397 \\
\hline PheSAUR44 & PH01002861G0060 & 334 & 323 \\
\hline
\end{tabular}


Table S2 The numbers of DST elements in downstream untranslated region

\begin{tabular}{|c|c|c|c|}
\hline Name & Gene ID & $\begin{array}{l}\text { Number of motif ATAGAT (or a } \\
\text { variation only at the first nucleotide } \\
\text { position) }\end{array}$ & $\begin{array}{l}\text { Number of } \\
\text { motif GTA }\end{array}$ \\
\hline PheSAUR1 & PH01000001G1450 & 2 & 5 \\
\hline PheSAUR2 & PH01000003G0680 & 0 & 3 \\
\hline PheSAUR4 & PH01000052G0130 & 1 & 15 \\
\hline PheSAUR5 & PH01000057G0880 & 0 & 3 \\
\hline PheSAUR6 & PH01000084G0620 & 0 & 1 \\
\hline PheSAUR7 & PH01000105G0420 & 1 & 5 \\
\hline PheSAUR8 & PH01000110G0260 & 2 & 13 \\
\hline PheSAUR9 & PH01000164G1020 & 2 & 10 \\
\hline PheSAUR11 & PH01000300G0250 & 2 & 10 \\
\hline PheSAUR12 & PH01000300G0310 & 0 & 15 \\
\hline PheSAUR13 & PH01000338G0730 & 1 & 10 \\
\hline PheSAUR14 & PH01000402G1010 & 0 & 4 \\
\hline PheSAUR15 & PH01000407G0060 & 0 & 2 \\
\hline PheSAUR16 & PH01000548G0100 & 1 & 8 \\
\hline PheSAUR17 & PH01001308G0070 & 1 & 14 \\
\hline PheSAUR18 & PH01001346G0370 & 0 & 11 \\
\hline PheSAUR19 & PH01001542G0200 & 1 & 20 \\
\hline
\end{tabular}




\begin{tabular}{|c|c|c|c|}
\hline PheSAUR20 & PH01001832G0020 & 0 & 2 \\
\hline PheSAUR21 & PH01001866G0310 & 6 & 35 \\
\hline PheSAUR22 & PH01002017G0200 & 0 & 0 \\
\hline PheSAUR23 & PH01002025G0060 & 0 & 3 \\
\hline PheSAUR24 & PH01002316G0030 & 1 & 5 \\
\hline PheSAUR25 & PH01002921G0180 & 3 & 10 \\
\hline PheSAUR26 & PH01002921G0190 & 2 & 5 \\
\hline PheSAUR27 & PH01002921G0250 & 1 & 4 \\
\hline PheSAUR28 & PH01003140G0110 & 0 & 6 \\
\hline PheSAUR29 & PH01003399G0150 & 0 & 3 \\
\hline PheSAUR31 & PH01003710G0040 & 0 & 13 \\
\hline PheSAUR32 & PH01004171G0020 & 1 & 8 \\
\hline PheSAUR34 & PH01004534G0100 & 0 & 4 \\
\hline PheSAUR35 & PH01004534G0130 & 0 & 5 \\
\hline PheSAUR36 & PH01006019G0010 & 1 & 7 \\
\hline PheSAUR37 & PH01006114G0030 & 0 & 0 \\
\hline PheSAUR38 & PH01015485G0020 & 0 & 2 \\
\hline PheSAUR41 & PH01000012G1930 & 2 & 6 \\
\hline PheSAUR42 & PH01000114G0400 & 1 & 2 \\
\hline PheSAUR43 & PH01000345G0270 & 0 & 7 \\
\hline PheSAUR44 & PH01002861G0060 & 1 & 3 \\
\hline
\end{tabular}


Table S3 Primers of PheSAUR genes used for qRT-PCR analysis

\begin{tabular}{|c|c|c|c|}
\hline Name & Gene ID & $\begin{array}{c}\text { Forward } \\
\text { (F)/Reverse } \\
\text { (R) }\end{array}$ & sequence \\
\hline \multirow{4}{*}{ PheSAUR1 } & & $\mathrm{F}$ & CAACAATGGTGGATTCGTGG \\
\hline & PH01000001G1450 & & \\
\hline & & $\mathrm{R}$ & CACGGACAGGGAGAGTAAAA \\
\hline & & $\mathrm{F}$ & TGATGTGGTAGTACTATTGGGTT \\
\hline \multirow[t]{2}{*}{ PheSAUR2 } & PH01000003G0680 & & \\
\hline & & $\mathrm{R}$ & TGTGATGAGATGAGAACAGATCA \\
\hline PheSAUR4 & PH01000052G0130 & $\mathrm{R}$ & $\begin{array}{l}\text { AAATGAGGCTAAGTTAAACGGAG } \\
\text { AAGGTGTCCAAAGCATCATAAAA }\end{array}$ \\
\hline \multirow[t]{2}{*}{ PheSAUR5 } & PH01000057G0880 & $\mathrm{R}$ & $\begin{array}{l}\text { GTGAAGTGAGATGGCTGAGA } \\
\text { GGATTTGACAAGGGAAGGGA }\end{array}$ \\
\hline & & $\mathrm{F}$ & CGGTTTAGAATTTACTCTACTGCC \\
\hline \multirow[t]{2}{*}{ PheSAUR6 } & PH01000084G0620 & $\mathrm{R}$ & GTTGCATTACCCAATCCAGATC \\
\hline & & $\mathrm{F}$ & TCGACCGCTGATTAATACGA \\
\hline \multirow[t]{3}{*}{ PheSAUR7 } & PH01000105G0420 & & \\
\hline & & $\mathrm{R}$ & CCATGTTCATATGTGTGCGT \\
\hline & & $\mathrm{F}$ & TAACCTGCTTTGAGTTCGATTG \\
\hline \multirow[t]{2}{*}{ PheSAUR8 } & PH01000110G0260 & $\mathrm{R}$ & ATCATCAGCAACTCCATCGATA \\
\hline & & $\mathrm{F}$ & AGAGCTTCTGTTCTCCTTCAG \\
\hline PheSAUR9 & PH01000164G1020 & $\mathrm{R}$ & CATGCCCCAAAATTCCAGAA \\
\hline PheSAUR11 & PH01000300G0250 & $\mathrm{F}$ & GCTTAGTGTCTCCGATCCTG \\
\hline & & 1 & \\
\hline
\end{tabular}




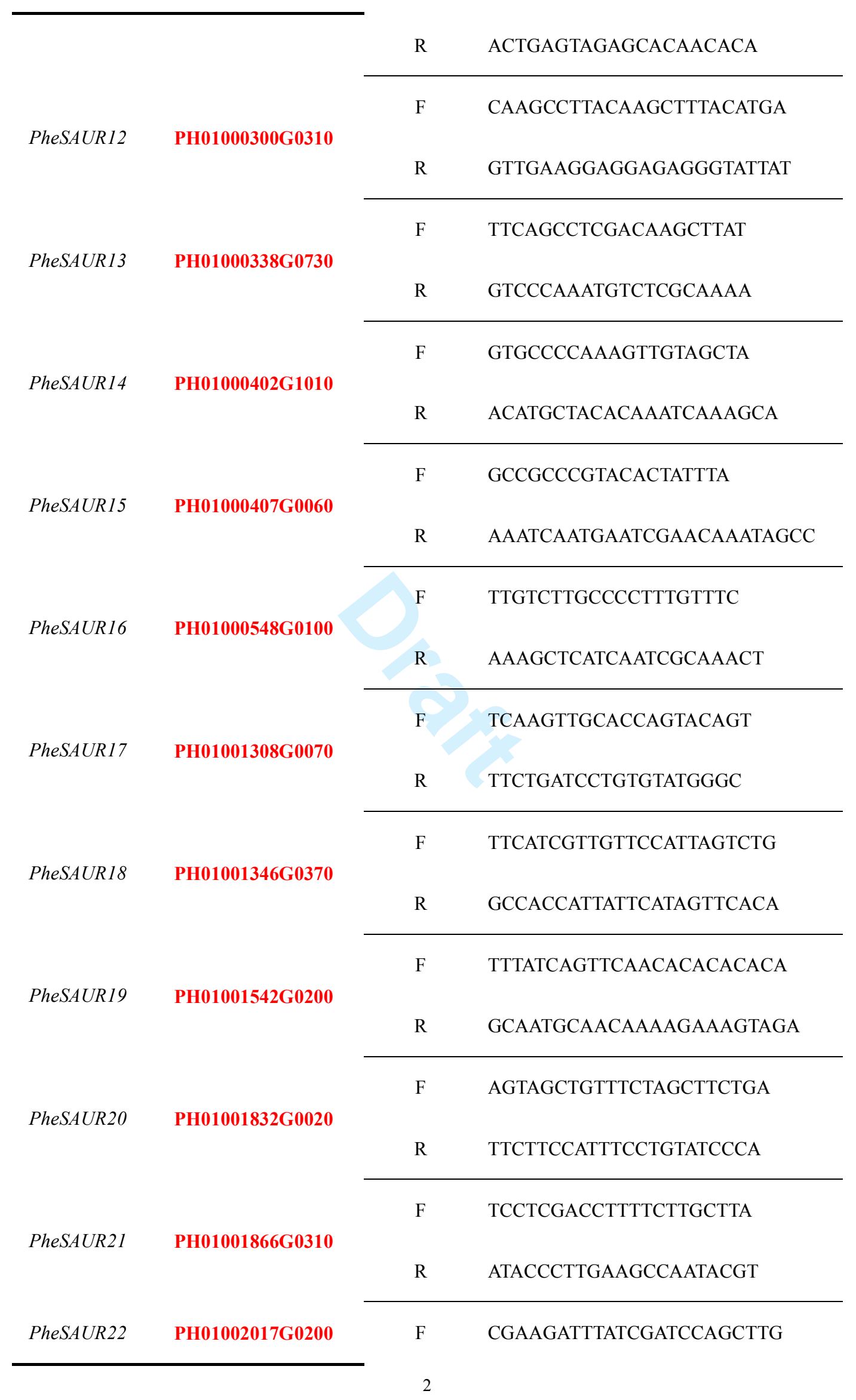




\begin{tabular}{|c|c|c|c|}
\hline & & $\mathrm{R}$ & GTCTCСТCСАТСТССТССТC \\
\hline \multirow{3}{*}{ PheSAUR23 } & & $\mathrm{F}$ & ACATAGGTCATTTAGCAGGCT \\
\hline & PH01002025G0060 & & \\
\hline & & $\mathrm{R}$ & CTGGTGTCTGGTAGTAACGT \\
\hline \multirow{3}{*}{ PheSAUR24 } & & $\mathrm{F}$ & ACTTGTTCTTCTTTTCCTAGGGA \\
\hline & PH01002316G0030 & & \\
\hline & & $\mathrm{R}$ & ACTAGCAATTTCCTCCATTTCAC \\
\hline \multirow{3}{*}{ PheSAUR25 } & & $\mathrm{F}$ & GGAACGTATGCCACTCTTATTTT \\
\hline & PH01002921G0180 & & \\
\hline & & $\mathrm{R}$ & GGTCGTTACAGTACTTCACATTT \\
\hline \multirow{3}{*}{ PheSAUR26 } & & $\mathrm{F}$ & AAAATGTGCATAAGTGAAAGAACC \\
\hline & PH01002921G0190 & & \\
\hline & & $\mathrm{R}$ & TATACTGACAAATAAAACCGGCTT \\
\hline \multirow{3}{*}{ PheSAUR27 } & & $\mathrm{F}$ & GGTCTTAGCCAATCACTACCTATA \\
\hline & PH01002921G0250 & & \\
\hline & & $\mathrm{R}$ & CACATTACATCACATGAAGATTTACC \\
\hline \multirow{3}{*}{ PheSAUR28 } & & $\mathrm{F}$ & TTGTCCTCAGATGATTGCCT \\
\hline & PH01003140G0110 & & \\
\hline & & $\mathrm{R}$ & CAGTACACATGAGAGCACGA \\
\hline \multirow{3}{*}{ PheSAUR29 } & & $\mathrm{F}$ & TTGTTTGATAAGAGGAAATGCGTA \\
\hline & PH01003399G0150 & & \\
\hline & & $\mathrm{R}$ & GGTGAAAGAGAGAAGAAAATGCTA \\
\hline \multirow{3}{*}{ PheSAUR31 } & & $\mathrm{F}$ & GGGCGAGTGAGTAATTAAAATGA \\
\hline & PH01003710G0040 & & \\
\hline & & $\mathrm{R}$ & CGGTAATGACACTGTTAATCTCC \\
\hline \multirow{3}{*}{ PheSAUR32 } & & $\mathrm{F}$ & GTGAGATGCAAACAACGACA \\
\hline & PH01004171G0020 & & \\
\hline & & $\mathrm{R}$ & GACAACCCAATCACCACAAC \\
\hline \multirow{3}{*}{ PheSAUR34 } & & $\mathrm{F}$ & TTGCCGTGTACTCTTTGTGT \\
\hline & PH01004534G0100 & & \\
\hline & & $\mathrm{R}$ & CCACCTTCCTTGATTGCTTG \\
\hline PheSAUR35 & PH01004534G0130 & $\mathrm{F}$ & CAGAGTTTTGCCCTGTTTGT \\
\hline
\end{tabular}

https://mc06.manuscriptcentral.com/genome-pubs 


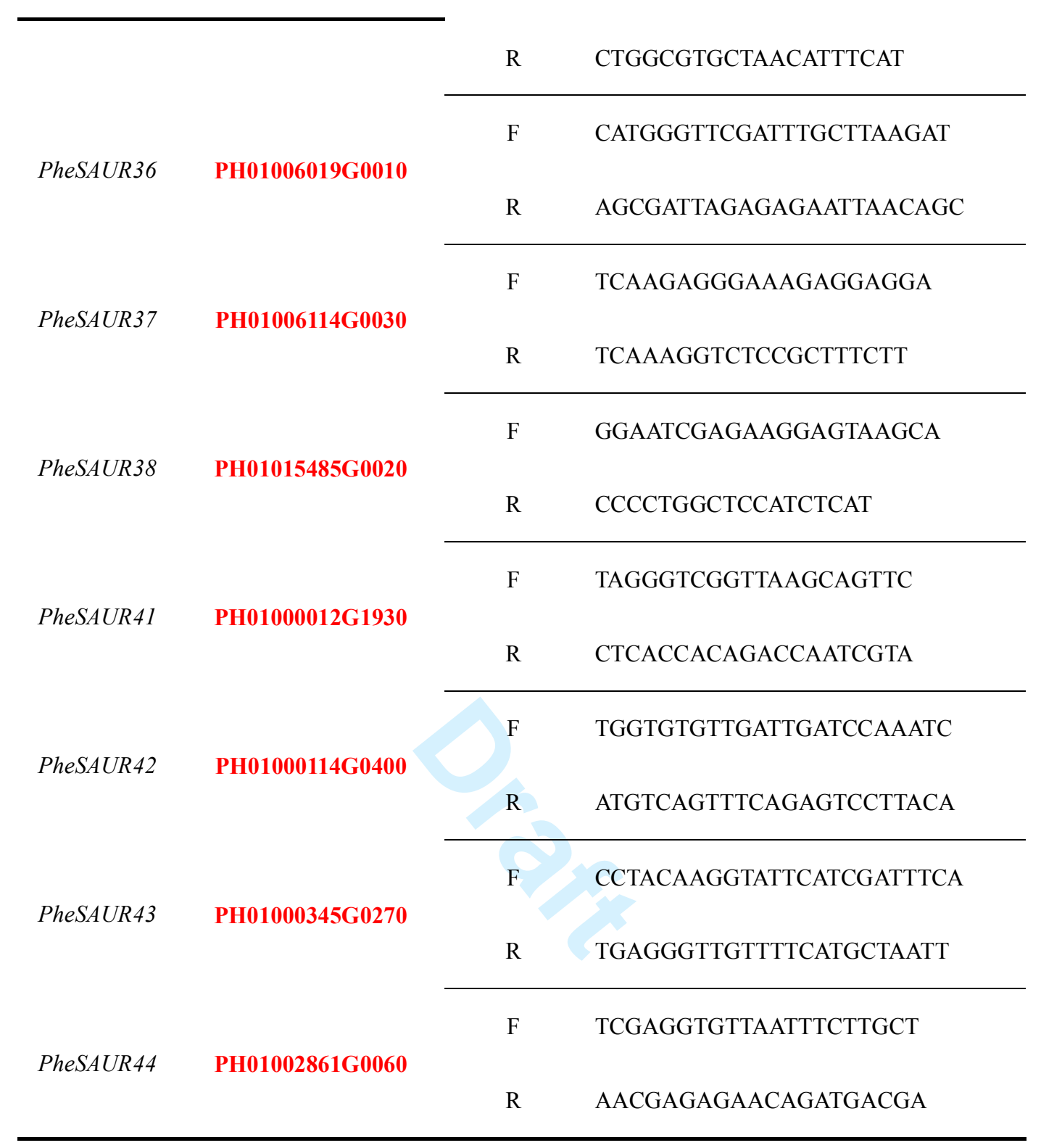


Table S4 Transcriptome FPKM value of PheSAUR genes at 8 different heights of shoots and culms

\begin{tabular}{|c|c|c|c|c|c|c|c|c|c|}
\hline Name & Gene ID & $0.1 \mathrm{~m}$ & $0.5 \mathrm{~m}$ & $1 \mathrm{~m}$ & $3 \mathrm{~m}$ & $6 \mathrm{~m}$ & $9 \mathrm{~m}$ & $12 \mathrm{~m}$ & $\mathrm{CK}(15 \mathrm{~m})$ \\
\hline PheSAUR1 & PH01000001G1450 & 0.238399 & 0 & 0.040608 & 0.531424 & 0.091154 & 0.165218 & 0.209561 & 0.783899 \\
\hline PheSAUR2 & PH01000003G0680 & 0 & 0.339284 & 0.207312 & 1.00812 & 0 & 0 & 0 & 0 \\
\hline PheSAUR4 & PH01000052G0130 & 0.25989 & 1.32177 & 1.46806 & 0.416624 & 0.972593 & 1.76392 & 1.95883 & 0 \\
\hline PheSAUR5 & PH01000057G0880 & 8.69593 & 8.22589 & 9.06753 & 0.577953 & 3.2346 & 1.29457 & 3.68508 & 0.117531 \\
\hline PheSAUR6 & PH01000084G0620 & 1.5099 & 0.29722 & 0.365117 & 0.808685 & 0 & 0 & 0.240336 & 0 \\
\hline PheSAUR7 & PH01000105G0420 & 0 & 0.063198 & 0.057461 & 0 & 0 & 9.33936 & 0.069771 & 4.46281 \\
\hline PheSAUR8 & PH01000110G0260 & 0 & 0 & 0 & 0 & 0 & 4.59367 & 0.112032 & 1.74821 \\
\hline PheSAUR9 & PH01000164G1020 & 0.25783 & 0 & 0 & 0 & 0 & 0.053235 & 0.050309 & 0 \\
\hline PheSAUR11 & PH01000300G0250 & 1.2787 & 1.86998 & 1.03571 & 3.09127 & 4.85629 & 2.07223 & 0.698749 & 16.4721 \\
\hline PheSAUR12 & PH01000300G0310 & 0 & 0 & 0 & 0.063421 & 0.064841 & 0.077262 & 0.072608 & 0.431536 \\
\hline PheSAUR13 & PH01000338G0730 & 1.08455 & 1.69019 & 1.83147 & 0.297877 & 1.39191 & 0.506291 & 0.204044 & 1.84008 \\
\hline PheSAUR14 & PH01000402G1010 & 0.452957 & 0.684589 & 0.15558 & 0.508328 & 0.886649 & 55.3061 & 6.01933 & 70.5448 \\
\hline PheSAUR15 & PH01000407G0060 & 0 & 0.870805 & 1.72627 & 0.128695 & 0.131402 & 0.319152 & 0.308355 & 0.19651 \\
\hline PheSAUR16 & PH01000548G0100 & 5.27703 & 4.00668 & 4.58403 & 7.77211 & 4.10484 & 5.18857 & 4.91773 & 4.37797 \\
\hline PheSAUR17 & PH01001308G0070 & 0.519692 & 1.31016 & 1.03549 & 1.70057 & 0.514573 & 20.182 & 3.05086 & 32.776 \\
\hline PheSAUR18 & PH01001346G0370 & 0 & 0 & 0 & 0 & 0 & 0 & 0 & 0 \\
\hline PheSAUR19 & PH01001542G0200 & 2.2913 & 2.94281 & 4.76682 & 2.52187 & 5.88824 & 2.6819 & 1.27398 & 16.5764 \\
\hline PheSAUR20 & PH01001832G0020 & 1.04974 & 1.34607 & 2.97842 & 0.222484 & 0.226025 & 1.09861 & 0.514694 & 0 \\
\hline
\end{tabular}




\begin{tabular}{|c|c|c|c|c|c|c|c|c|c|}
\hline PheSAUR21 & PH01001866G0310 & 0.530307 & 1.01901 & 3.63868 & 0.026443 & 0.079263 & 2.17467 & 0.634594 & 0.691474 \\
\hline PheSAUR22 & PH01002017G0200 & 1.02654 & 9.02713 & 17.5585 & 2.55931 & 1.52753 & 2.68893 & 3.85556 & 0 \\
\hline PheSAUR23 & PH01002025G0060 & 0.113015 & 1.09779 & 0.058723 & 0.382449 & 6.32658 & 3.72098 & 4.46079 & 0.94316 \\
\hline PheSAUR24 & PH01002316G0030 & 4.97948 & 1.38178 & 2.83484 & 1.87975 & 1.51126 & 3.14987 & 1.27049 & 8.15745 \\
\hline PheSAUR25 & PH01002921G0180 & 0.695561 & 1.93473 & 2.21018 & 4.48449 & 2.35552 & 1.40366 & 2.40372 & 1.73979 \\
\hline PheSAUR26 & PH01002921G0190 & 0.695561 & 1.93473 & 2.21018 & 4.48449 & 2.35552 & 1.40366 & 2.40372 & 1.73979 \\
\hline PheSAUR27 & PH01002921G0250 & 0.155847 & 0.065795 & 0 & 0.259294 & 0.259493 & 0.15859 & 0.075319 & 0.0802286 \\
\hline PheSAUR28 & PH01003140G0110 & 16.5349 & 2.25868 & 1.08377 & 3.68308 & 1.04483 & 3.59899 & 4.96179 & 1.23799 \\
\hline PheSAUR29 & PH01003399G0150 & 0 & 0 & 0.023756 & 0 & 0 & 0 & 0 & 0 \\
\hline PheSAUR31 & PH01003710G0040 & 4.7955 & 7.86176 & 7.0024 & 9.42338 & 3.45954 & 1.89812 & 3.00291 & 0 \\
\hline PheSAUR32 & PH01004171G0020 & 19.6366 & 11.4953 & 14.7051 & 0.253392 & 0.817853 & 1.74777 & 1.29828 & 0 \\
\hline PheSAUR34 & PH01004534G0100 & 0 & 0.088368 & 0.245363 & 0.088087 & 0 & 0.435946 & 0.103436 & 0.117665 \\
\hline PheSAUR35 & PH01004534G0130 & 0.771403 & 0.732269 & 1.81377 & 0.252667 & 0.671263 & 3.89851 & 1.91514 & 2.45801 \\
\hline PheSAUR36 & PH01006019G0010 & 0.191732 & 2.746 & 2.88193 & 3.40668 & 0.43985 & 5.13804 & 6.60921 & 6.0851 \\
\hline PheSAUR37 & PH01006114G0030 & 0.215018 & 0.182631 & 0.260692 & 0.634877 & 0.357897 & 1.22155 & 1.07533 & 1.39094 \\
\hline PheSAUR38 & PH01015485G0020 & 0 & 0.178194 & 0.165622 & 0.442405 & 0.35375 & 0.546556 & 0.922929 & 0.905248 \\
\hline PheSAUR41 & PH01000012G1930 & 0.327422 & 0.229035 & 0.168075 & 0 & 0.358984 & 6.00615 & 1.52938 & 101.464 \\
\hline PheSAUR42 & PH01000114G0400 & 11.5764 & 13.3291 & 8.58859 & 16.6493 & 10.4563 & 16.0201 & 10.6155 & 13.8312 \\
\hline PheSAUR43 & PH01000345G0270 & 0.070862 & 0.157456 & 0.216617 & 0 & 0.07949 & 7.74348 & 0.184518 & 47.6931 \\
\hline PheSAUR44 & PH01002861G0060 & 1.9647 & 2.425 & 2.09428 & 1.34111 & 1.93485 & 2.36954 & 1.35545 & 0.676737 \\
\hline
\end{tabular}

